Seton Hall University eRepository@Seton Hall

Seton Hall University Dissertations and Theses (ETDs)

Seton Hall University Dissertations and Theses

2011

\title{
Male Psychology Doctoral Students: The Influence of GRC on Training
}

Christopher A.T. Sbaratta

Seton Hall University

Follow this and additional works at: https://scholarship.shu.edu/dissertations

Part of the Clinical Psychology Commons, and the Higher Education Commons

\section{Recommended Citation}

Sbaratta, Christopher A.T., "Male Psychology Doctoral Students: The Influence of GRC on Training" (2011). Seton Hall University Dissertations and Theses (ETDs). 482.

https://scholarship.shu.edu/dissertations/482 
Male Psychology Doctoral Students: The Influence of GRC on Training

Christopher A. T. Sbaratta

Dissertation Committee:

Lewis Z. Schlosser, PhD, ABPP, Mentor

Pamela F. Foley, $\mathrm{PhD}, \mathrm{ABPP}$, Chair

Daniel S. Saland, PsyD

Cheryl Thompson Sard, PhD

Ben K. Beitin, PhD

Submitted in partial fulfillment of the requirements for the degree of Ph.D. in Counseling Psychology Seton Hall University 
(C) Copyright by Christopher A. T. Sbaratta, 2011 All Rights Reserved 


\section{SETON HALL UNIVERSITY \\ COLLEGE OF EDUCATION AND HUMAN SERVICES \\ OFFICE OF GRADUATE STUDIES}

\section{APPROVAL FOR SUCCESSFUL DEFENSE}

Doctoral Candidate, Christopher Sbaratta, has successfully defended and made the required modifications to the text of the doctoral dissertation for the $\mathbf{P h . D}$. during this Spring Semester 2011.

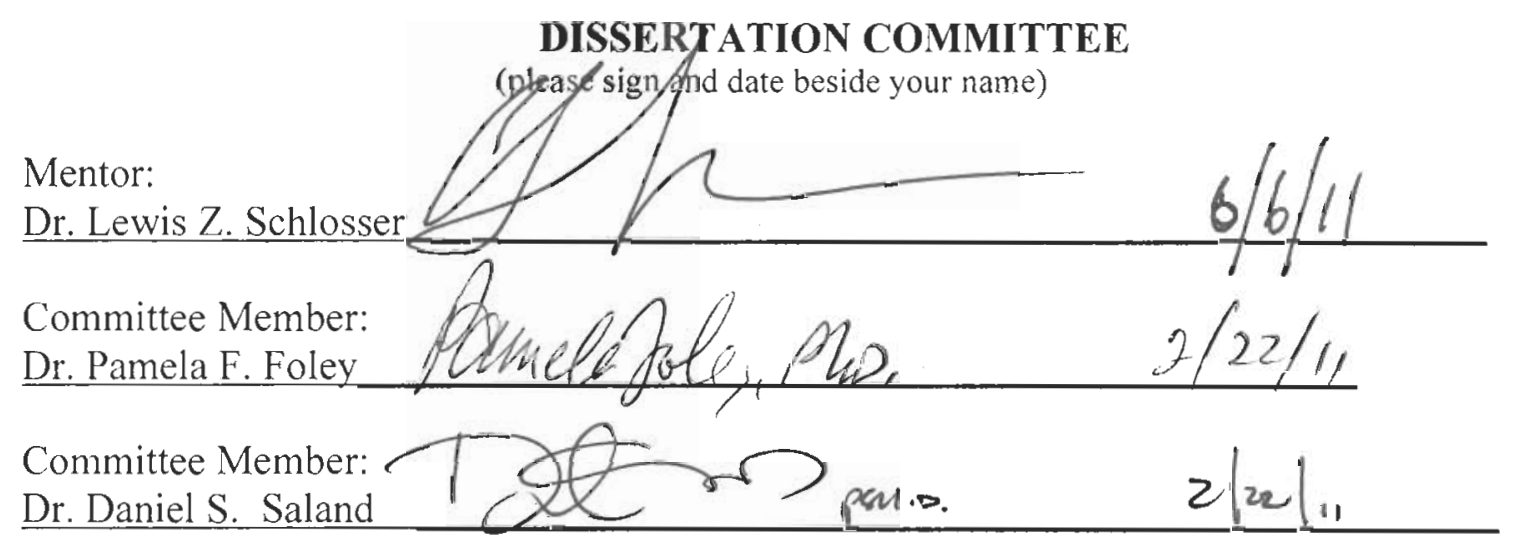

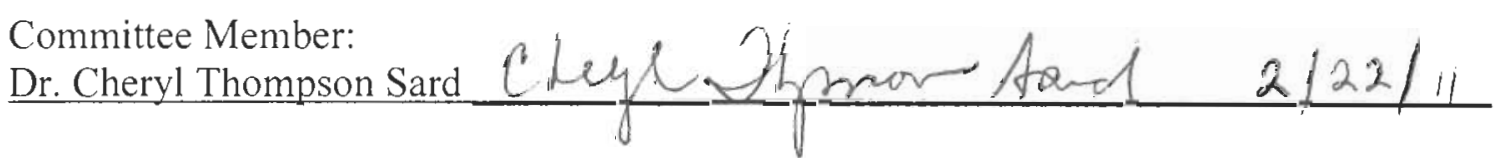

External Reader:

The mentor and any other committee members who wish to review revisions will sign and date this document only when revisions have been completed. Please return this form to the Office of Graduate Studies, where it will be placed in the candidate's file and submit a copy with your final dissertation to be bound as page number two. 


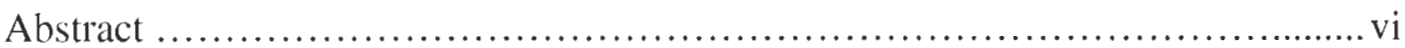

Acknowledgments..................................................... vii

Dedications................................................................. vii

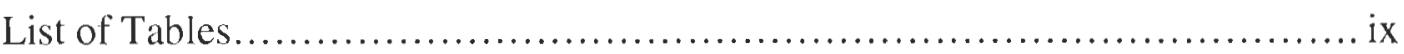

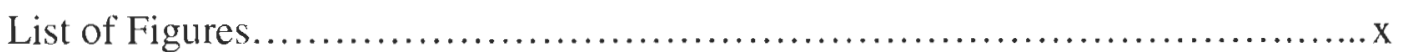

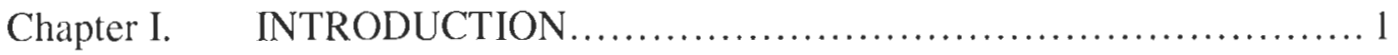

Statement of the Problem and Significance of the Study .................. 2

Further Rationale for Study of Male Psychology Students and GRC....... 5

Men in psychology do not experience significant GRC...........6 6

Men in psychology do not warrant scholarly focus.................. 7

Research Questions.................................................. 11

Research Hypotheses.............................................. 11

Conclusion..................................................... 12

Definitions........................................................

Chapter II. REVIEW OF LITERATURE............................... I5

The Graduate Training Environment in Psychology.................... 15

Training tasks and models.................................... 15

Common threads of psychological training..................... 16

The Place of Men in Psychology...................................... 17

GRC Theory: Operationally Defined Components....................... 18

The patterns of GRC.......................................... 19

The situational contexts of GRC........................... 19

Male Psychology Students and GRC Theory........................... 21

The intersection of GRC and male trainees....................... 21

The utility of GRC in this study.............................. 23

Extant Research on GRC in Relevant Contexts..........................24

Therapists' GRC......................................... 25

GRC and attitudes toward help-seeking......................... 26

GRC and vocational choice.................................... 27

Related Training Experience and Outcome Variables .....................29

The Advisory Relationship .......................................... 29

Advising defined........................................... 29

Existing advising research..................................... 31

Psychological Distress................................................. 36

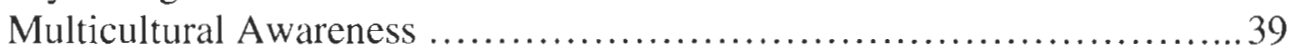

Conclusion......................................................... 42 
Participants......................................................44

Power Analysis.................................................... 44

Measures............................................................ 44

Gender Role Conflict Scale...................................... 45

Advisory Working Alliance Index - Student Version................46

Multicultural Awareness, Knowledge, and Skills Survey-

Counselor Edition-Revised $. . \ldots \ldots \ldots \ldots \ldots \ldots \ldots \ldots \ldots \ldots \ldots \ldots, 47$

Outcome Questionnaire........................................ 48

Demographic questionnaire................................... 49

Design........................................................... 50

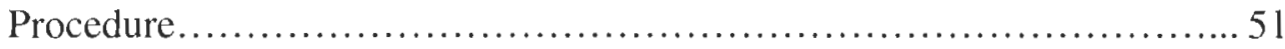

Participant recruitment...................................... 51

Chapter IV. RESULTS ................................................. 53

Description of Sample...............................................53

Descriptive statistics........................................ 54

Male Psychology Doctoral Students and GRC Norms...................58

Normative male GRC sample.............................. 59

One sample t-tests.......................................61

The Influence of GRC on Training Variables...........................66

Multiple regression analyses...................................................65

Exploratory Analyses.............................................67

Exploration of within-group differences on GRC ................. 69

Exploration of within-group differences on AWAI-S...............69 69

Conclusion........................................................ 70

Chapter V. DISCUSSION .............................................. 71

Interpretation of Findings....................................... 71

GRC among male psychology doctoral students............... 71

GRC and aspects of psychology training....................... 75

GRC and psychological distress............................... 76

GRC and the advisory working alliance ......................... 79

GRC and multicultural awareness............................ 80

Exploration of within-group differences......................... 83

Limitations of Current Study........................................ 86

Implications for Education and Training.............................. 91

Suggestions for Future Research................................. 93 


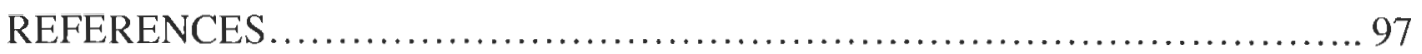

APPENDIX A: Demographic Questionnaire................................................... 111

APPENDIX B: Gender Role Conflict Scale (GRCS)........................ 113

APPENDIX C: Multicultural Awareness, Knowledge, and Skills Survey -

Counselor Edition - Revised (MAKSS-CE-R) - Awareness.........117

APPENDIX D: Advisory Working Alliance Index-Student Version (AWAI-S).....120

APPENDIX E: Outcome Questionnaire (OQ-45.2).......................................... 123

APPENDIX F: INFORMED CONSENT: Male Psychology Graduate Students..... 127

APPENDIX G: Recruitment Letter........................................ 129 


\begin{abstract}
Male Psychology Doctoral Students: The Influence of Gender Role Conflict on Training
\end{abstract}

The percentage of men entering and completing doctoral training programs in psychology has steadily decreased over the past several decades (Pion et al., 1996). Despite this significant numerical decline, and its obvious effect of the number of male psychologists entering the workforce, scholarship on this subgroup of men is scarce. In this study, 302 male psychology doctoral students completed measures that assessed the psychological effects of their gender role and related those effects to aspects of their training experience. The major aims of this study were to compare the gender role conflict (GRC) of male psychology doctoral trainees to that of a normative male sample and establish associations between GRC and (a) the advisory working alliance, (b) multicultural awareness, and (c) psychological distress. Results indicated that male trainees largely report less GRC than other men - yet, have greater gender related conflict between their work and family relations. Among these men, patterns of GRC were found to be predictive of psychological distress and multicultural awareness, but had no association with the advisory working alliance. Implications for training and directions for future research are provided.

Keywords: Men and Masculinity, Psychology Training, Gender Role Conflict, Advising 


\section{Acknowledgments}

I offer the sincerest of thanks to my mentor, Lew Schlosser, for his steadfast presence throughout my doctoral studies and generous assistance with this research. Furthermore, I am grateful for the expertise of all the members of my dissertation committee. Thank you for your accessibility, guidance and modeling. To my parents, Anthony and Christina, thank you for valuing my pursuits - endless appreciation for a lifetime of selfless backing. To my friends, your interests in my professional goals (and valuable distraction from them) have moved me forward during challenging times. Finally, to Cathy Altier, thank you for your continuous understanding and patience, for trusting in my abilities, and for all of your influences. 


\section{Dedications}

This manuscript is dedicated to the memory of my grandparents, whose sacrifices and contributions have made possible, not only the attainment of my doctoral degree, but the growth and freedom it represents. 


\section{List of Tables}

Table 1: $\quad$ Summary of Chi-Square Analysis of Racial Frequencies in Sample......57

Table 2: $\quad$ GRCS Studies of Diverse Men Used to Create Normative Male

Comparison Sample.

Table 3: $\quad$ Means of the GRCS, AWAI-S, OQ-45.2 and MAKSS-Awareness by

Cultural Demography

Table 4: Means, Standard Deviations, and Ranges of the GRCS, AWAI-S,

OQ-45.2 and MAKSS- Awareness.

Table 5: $\quad$ Summary of Multiple Linear Regression Analysis of GRCS Variables

Predicting OQ-45.2

Table 6: $\quad$ Summary of Multiple Linear Regression Analysis of GRCS Variables

Predicting MAKSS-Awareness.

.82 


\section{List of Figures}

Figure 1: $\quad$ Normative GRC data example from The Gender Role Conflict

Research Program...... .60 


\section{CHAPTER I}

\section{Introduction}

Across three decades, the psychology of men and masculinity has steadily emerged as a vital area of scholarly and clinical interest. This growing attention parallels psychologists' burgeoning awareness of male gender socialization, the components of masculine identity, and the impact of masculinity across various aspects of men's lives (O’Neil, 2008; Smiler, 2004). Researchers in this area have postulated a relationship between male gender roles and the psychological problems experienced by men. That is, the male socialization process confines, strains and ultimately limits men from becoming fully functioning human beings (O’Neil, Good \& Holmes, 1995; Pleck, 1981). Pioneered by O'Neil (1981a, 1981b, O'Neil, Helms, Gable, David, \& Wrightsman, 1986), this model of masculine theory, coined Gender Role Conflict (GRC), describes "a psychological state in which socialized gender roles lead to negative outcomes or consequences" (O'Neil, et al., 1995, p. 166) for the individual or others in his life. The costs of a restrictive male gender role were theorized to manifest in distinct domains (i.e., cognitive, behavioral, affective, and unconscious). The conceptual GRC model inspired psychologists to empirically examine the effects of male gender role socialization. This line of research began with the development of empirically derived patterns, or types, of GRC (e.g., conflict between work and family, restrictive emotionality). These individual patterns are the measurable, behavioral expressions of conflict stemming from socially learned and reinforced expectations for masculinity within the United States (O'Neil, 2008). To date, researchers have explored GRC in over 230 studies, yielding significant implications regarding men's functioning and overall psychological health (O'Neil, 
2008). This impressive line of research has solidified the importance of GRC vis-à-vis the study of men and masculinity.

\section{Statement of the Problem and Significance of the Study}

Despite this significant amount of empirical consideration, the experience of gender role conflict among those providing, or training to provide therapeutic services has gone understudied. In fact, a thorough literature review yielded only three empirical studies that examined GRC among male practitioners and graduate students in clinical settings. In sum, these researchers found that increased aspects (i.e., patterns) of GRC among practitioners produced more negative interactions (i.e., poorer prognosis, less empathy) with nontraditional male clients (Hayes, 1985; Wisch \& Mahalik, 1999), and negatively affected both clinical self-efficacy and supervisory working alliance (Wester, Vogel, \& Archer, 2004). These studies, though few in number, introduced ways in which GRC manifests among males within the context of psychology practice and training. Furthermore, such findings suggest that training needs should address how such conflicts negatively affect men in psychology and, by extension, the individuals they serve (O’Neil, 2008).

In a critical, conceptual article, Wester and Vogel (2002) championed the need for psychologists to examine and understand the role of GRC in male psychologists' clinical performance, self-efficacy, and training. These researchers concluded with a call for future researchers to "continue to explore the relationship between GRC and men's training experience," (p. 374) and "not only to improve the training experiences of men but also to further the psychology of men as a whole" (p.374). In another conceptual article, MacKinnon, Bhatia, Sunderani, Affleck, and Smith (2011) propose the utilization 
of feminist-informed theories of clinical supervision to address the needs of male supervisees. These authors state that "future research is needed to examine the experience of culturally diverse men....and its relation to GRC" (p. 134). Ipso facto, these scholars provide significance to the current study - an empirical investigation of GRC as it relates to male psychology students within the doctoral training environment.

It follows, then, that an investigation of these men should focus on factors relevant to the psychology training environment. For example, there has been some recent scholarship regarding the ways in which multicultural factors impact studentfaculty relationships in doctoral training (Schlosser \& Foley, 2008). Furthermore, the advisory relationship has been recognized as an integral element of graduate training (Knox, Schlosser, Pruitt, \& Hill, 2006; Schlosser \& Gelso 2001, 2005; Schlosser, Knox, Moskovitz, \& Hill, 2003) and has been found to be related to a number of positive training outcomes (Schlosser \& Gelso, 2001, 2005; Schlosser \& Kahn, 2007). However, psychologists have not attended to the call made by some of these researchers (e.g., Schlosser \& Gelso, 2001, 2005) to empirically examine how dimensions of personal identity (e.g., race, gender, religion, sexual orientation) affect the development and maintenance of the advisory working alliance. Thus, as gender is an important aspect of diversity, an exploration of GRC could inform how aspects of male gender identity influence the experience of the graduate advising relationship In addition to the advisory working alliance, I also explored male trainees' multicultural awareness and psychological distress with regard to GRC. These factors (i.e., multicultural awareness, psychological distress) were believed to be both (a) present in the contemporary graduate training environment and, (b) empirically related to GRC. 
The purpose of this study, then, was to describe the experience of male psychology doctoral students with the intent of informing and extending the existing knowledge regarding GRC and three related dimensions of psychology training - namely, the advisory relationship, multicultural awareness and psychological distress.

The inclusion of multicultural awareness into this examination is fitting given the attention that diversity and multicultural competencies receive within contemporary psychological practice and training (American Psychological Association, 2003; Tori, \& Ducker, 2004). More specifically, graduate programs have increasingly incorporated the study of diversity and multiculturalism into their training curricula (i.e., coursework, clinical training, research; e.g., Liu, Sheu, \& Williams, 2004; Rogers, Hoffman, \& Wade, 1998). Thus, attention to multicultural skills is a noted part of the training environment and experience of doctoral students. In addition, a line of research (see O'Neil, 2008 for a complete review) has demonstrated relationships between patterns of GRC and biased attitudes towards women and other marginalized groups (e.g., racial/ethnic minorities, lesbian, bisexual, gay, transgendered persons). Therefore, the inclusion of this aspect of psychological training (i.e., multicultural awareness) is warranted, given its potentially negative relationship to GRC.

The inclusion of psychological distress into this study was based on a significant number of research findings (see O'Neil, 2008 for a complete review), which show GRC to be significantly correlated with many psychological difficulties (e.g., anxiety, depression, stress). Given the demands and rigors of the graduate training environment, these data make a persuasive case for the inclusion of male students' experience of psychological distress into this study. In addition, global competencies for practicing 
psychology involve "emotional fitness requirements" (Johnson \& Campbell, 2002, p. 46). For male students in training, the potential exists for some combination of GRC and psychological distress to lead to diminished competency and impairment during training. Hence, the relationships between GRC and psychological distress during graduate training necessitate empirical attention.

Lastly, in addition to the aforementioned purpose of this study, a description of the sample was provided that is inclusive of additional dimensions of identity (e.g., race, sexual orientation) and other demographics (e.g., specialty of doctoral program). Scholars (e.g., O'Neil, 2008; Thompson, Pleck, \& Ferrera, 1992) have cited a need for the study of masculinity and GRC to be aware of the multidimensional nature of these constructs and consequently, inclusive of variables related to individual differences in future research. Thompson et al. stated "we are largely unfamiliar with how age, generation, sexual orientation, class, race, and ethnicity, differentially structure the form and content of men's lives and the standards of masculinity to which they adhere" (p. 602). Thus, this study will attend to the intersection of secondary identity dimensions in order to provide a richer description of this sample of men. This was made possible by soliciting demographic information from participants. Descriptive statistics will be presented. Also, further power analyses were run to determine the permissibility of exploring withingroup differences (e.g., gay and heterosexual male doctoral students) with regards to both GRC and the advisory working alliance.

\section{Further Rationale for Study of Male Psychology Students and GRC}

Despite the heretofore-mentioned value of researching this population, its limited empirical investigation prompts curiosity. Within doctoral psychology training programs, 
attending to cultural identity is imperative, as personal similarities and differences can affect students and faculty within interpersonal and intrapersonal spheres. For students, who are charged with cultivating professional relationships with their cohort peers and faculty, issues of power, privilege and ingroup-outgroup dynamics are salient to the training environment. It is curious, then, that little is known about the gendered experience of male psychology trainees.

Possible suppositions as to why such a paucity of research exists on GRC as it pertains to men in psychology include: (a) that men in psychology do not experience significant conflict with their socialized gender roles, and (b) that men in the field do not warrant specific scholarly focus. The former explanation suggests a belief that men who pursue a career in psychology are nontraditional males, and thus, are immune to the deleterious effects of GRC. The latter explanation may stem from ambiguous feelings about the appropriateness of studying men given their historical and current position of privilege in the larger society in general, and the psychology profession in particular. This dynamic could be akin to the early questioning of such models as White racial identity development (Helms, 1984) and the larger inclusion of Whites within the realm of multiculturalism (Liu, 2005). These two possible explanations and their underlying beliefs will be briefly expanded upon and challenged in order to further stress the need for an empirical investigation of male doctoral psychology students and GRC.

Men in psychology do not experience significant GRC. Despite a small line of research demonstrating that high GRC is both more evident in career traditional men, and reciprocally predictive of traditional career choice (Dodson \& Borders, 2006; Jome \& Tokar, 1997; Tokar \& Jome, 1998), there is currently insufficient research on GRC and 
men's career choice (O’Neil, 2008). Therefore, as no prior research has compared the GRC of men in psychology to a normative male sample, assumptions regarding the manifestations of masculinity among men in the field of psychology should not be made. Rather, in the absence of existing data, it is imperative to acknowledge that the gender role socialization processes, and subsequent psychological effects, are arguably similar for all men socialized and indoctrinated within patriarchal and sexist societies (Mintz \& O'Neil, 1990; O'Neil et al., 1986; Wisch \& Mahalik, 1999). Thus, a need exists to evaluate men in psychology against a normative male sample vis-à-vis GRC to establish their relative place on the continuum of conflict with masculine norms.

Men in psychology do not warrant scholarly focus. To address potentially ambivalent feelings regarding the need to study male students given their privileged status, I begin with a discussion of the gender composition within psychology training programs, past and present. It is important to recognize that males in contemporary psychology training programs exist in an ever-changing demographic environment with regards to gender composition. Pion et al. (1996) noted that the field of psychology has undergone, and continues to undergo a marked shift in gender composition. Recent data from the American Psychological Association Center for Workforce Studies (CWS) indicate that, roughly $24 \%$ of all doctoral recipients in 2007 were men (American Psychological Association, 2009a). Similarly, data from The APA Commission on Accreditation and APA Office of Program Consultation and Accreditation, Research Committee indicate that males constitute approximately $23 \%$ of APA-accredited clinical and counseling psychology doctoral students (American Psychological Association, 2010). These statistics juxtapose clearly against data from 1973, which revealed that men 
comprised nearly $80 \%$ of psychology, Ph.D. recipients in the workforce - a percentage that shrank to $50 \%$ by 2006 (Hart, 2009). Such differences in gender composition are also evident within psychological specialty. Specifically, within the field of counseling psychology, approximately $35 \%$ of Ph.D. recipients in 2006 were male, with females constituting the majority among counseling psychologists in 2008 (American Psychological Association, 2008; Munley, Pate, \& Duncan, 2008). Among counseling psychologists there has been a clear gender shift over time - with men an $80 \%$ majority in the mid-1980's (Fitzgerald, \& Osipow, 1986; Munley, Pate, \& Duncan, 2008). While the increased representation of women is an encouraging change within the field (Pion et al.), this gender shift also naturally seeks explanation for fewer male students seeking and completing psychology doctoral degrees.

Furthermore, such shifts in gender composition creates the opportunity to consider the gendered experiences of men training to be psychologists and rouse greater scholarly interest into the manifestations of masculinity in the graduate training environment. Apropos, in this study, I assert that male professionals and students have become a privileged minority (e.g., Evans, 1997) in the field of psychology. This status among males in the field is the product of simultaneously enjoying societal power and privilege, while remaining a statistical minority in the gender composition of the profession. Scholars in other disciplines have used this construct in order to connote the intersection of a particular group's societal privilege with a minority status within the larger population. For example, in the experience of male nurses, Villeneuve (as cited in Evans, 1997, p. 227) states that despite their smaller numbers within the total profession, these men retain patriarchal power and status. Another illustration of this concept is 
provided by Bowen (1983) with regards to the privileged minority status of Protestants within the majority Catholic population of Ireland. Therefore, while it may be the case that male psychologists and male psychology students differ from traditional males in various ways (e.g., adherences to masculine norms, nature of vocational choice, emotional expressiveness), they have still been developmentally socialized with male ideology and thus have organized their identity accordingly to a certain extent (Wisch \& Mahalik, 1999). As a result, men in psychology must manage and negotiate this aspect of their identity within a unique context. Nevertheless, whether or not male psychologists and psychology students differ from other, more traditional, males is a subject for empirical scrutiny - hence the current study.

Regardless of any hypothesized cause for this gap in existing literature, the rationale for this study was predicated upon two major needs within the psychology of men and masculinity. First, this exploration of men within this context will further emphasize the much-needed inclusion of masculinity into the framework of multiculturalism. Secondly, an empirical focus on GRC may be concurrently (a) germane to male students, given their minority status within the training environment, and (b) prudent, given the potentially limiting and detrimental effects of GRC on men or those in their lives.

Despite decades of scholarship, it was not until recently that Liu (2005) conceptually bridged the psychology of men and masculinity to multiculturalism. This link was well warranted given the long held assumption that men constitute a unique culture, with socialized and circumscribed values, norms and expectations to which they must adhere. Akin to the inclusion of other diverse groups into multiculturalism, the 
explicit study of the male gender was needed in order to promote professional competencies and ethical practices with regards to men and masculinity. Multicultural competency involves the acquisition of knowledge, awareness and skills (Sue,

Arredondo, \& McDavis, 1992, Sue \& Sue, 2003) so as to develop both the ability to effectively work with diverse groups and the understanding of oneself as a cultural being.

Thus, for psychologists involved in graduate training, as well as trainees, this study reinforces the presence of masculinity as a salient dimension of multiculturalism, and by extension, clinical practice. It has also begun to describe the gendered dynamics experienced by male psychology doctoral students, thereby increasing self-awareness among these students vis-à-vis their distinctive masculinity. As a result, men in psychology can become increasingly "aware of their own stereotypes, attributions and expectations of men (Liu, 2005, p. 689);" both of themselves and the male clients they work with. Since GRC has enjoyed a substantial place, both conceptually and empirically, within the study of men and masculinity literature, it has likely served as a sound platform from which to begin the examination of this understudied population.

GRC is considered an important construct for contemporary psychological research (e.g. O'Neil, 2008). However, some have noted that specific areas for future exploration have not been explicitly identified (i.e., Enns, 2000). This study begins to answer this call, demarcating GRC and male psychology graduate students as an explicit area for empirical consideration. GRC is a deficit model of masculinity, which addresses the costs experienced as a result of the confines of the male gender role. Despite recent movements by researchers towards the inclusion of alternate and underutilized models of masculinity (i.e., positivistic masculinity; Kiselica, Englar-Carlson, Horne \& Fisher, 
2008; Wester, Vogel, Pressly, \& Heesacker, 2002), I view the utilization of the GRC construct as a crucial first step in the study of male psychology students. The decision to utilize a deficit model (e.g., Doherty, 1991) was informed by the primary need to expose potentially deleterious outcomes (i.e., poor advisory working alliance, low multicultural awareness, experience of psychopathology) of the restrictive male gender role in doctoral training - as such potential consequences restrict and affect not only male trainees, but also ultimately the public that they serve.

Thus, the empirical inclusion and description of male psychology trainees, coupled with the potential effects associated with GRC, will better inform psychologists as to the gendered experience of this group of men. I hoped to cast important light on this unique group of men and provide an initial footing for future research (e.g., into the decreased number of men entering psychology graduate programs). Specifically, the following research questions and hypotheses have been addressed in this study:

\section{Research Questions}

1. How do male psychology doctoral students' experiences of gender role conflict compare to a normative male sample?

2. How do patterns of gender role conflict influence male psychology doctoral students' (a) advisory working alliance, (b) multicultural awareness, and (c) psychological distress?

\section{Research Hypotheses}

1. Compared to a normative sample of men, male psychology doctoral students will report lower overall scores on the Gender Role Conflict Scale and each of its four subscales (i.e., Success Power Competition (SPC), Restrictive Emotionality (RE), 
Restrictive Affectionate Behavior Between Men (RABBM), and Conflict Between Work and Family Relations (CBWFR)).

2. Specific Gender Role Conflict Scale subscale scores (i.e., RE, SPC, CBWFR) will predict psychological distress (OQ-45.2) among this sample of doctoral students. In addition, specific GRCS subscale scores (i.e., RE, SPC) will predict advisory working alliance (AWAI-S). No hypothesis was offered regarding the predictability of GRCS subscale scores on multicultural awareness (MAKSS - AWARENESS).

\section{Conclusion}

In sum, my purpose was to broaden the scope of the literature addressing GRC by examining the experience of male psychology doctoral students. In this aim, I also intended to add to the current body of research related to dimensions of psychology training, such as the advisory working alliance. I (a) compared the reported GRC patterns of male psychology doctoral students to that of a normative male sample in order to describe these students' negative experiences of male socialization against those of other men; (b) established the predictive power of patterns of GRC on the advisory working alliance, multicultural awareness, and psychological distress; and (c) provided a description of this sample of men that is inclusive of additional dimensions of identity (e.g., race, sexual orientation) and other demographics (e.g., specialty of doctoral program). Before beginning, I review the current literature on GRC to contextualize our discussion and form a clear platform for which to review the training experiences and variables salient to this construct. 


\section{Definitions}

Gender Role Conflict (GRC): Gender Role Conflict is defined as "a psychological state in which socialized gender roles have negative consequences on the person or others.

Gender role conflict occurs when rigid, sexist, or restrictive gender roles, learned during socialization, result in personal restriction, devaluation, or violation of others or self" (O'Neil et al., 1995, p. 166).

Male Psychology Trainee: Male psychology trainees have been operationally defined as a participant who has identified as currently enrolled in an APA accredited counseling or clinical graduate program in psychology on the demographic form located in Appendix A.

Gender Role Norms: Gender role norms are defined as rules and standards that influence, guide and constrain masculine and feminine behavior. Gender role norms are activated when individuals either are told, or observe, how most men and women behave socially, and the relative appropriateness of these gendered behaviors. Thus, these norms are the product of learned expectations regarding behaviors tied to one's gender (Mahalik, Good, \& Englar-Carson, 2003).

Masculine Ideology: Masculine ideology refers to "beliefs about the importance of men adhering to culturally defined standards for male behavior" and involves "the individual's endorsement and internalization of cultural belief systems about masculinity and male gender, rooted in the structural relationships between the sexes" (Pleck, 1995, p. 19). Traditional Masculinity: Traditional masculinity is the term used to describe masculinity ideology as the sum of contemporary attitudes and behaviors in the United States 
considered stereotypically male. These include emotional control, anti-femininity, homophobia, and achievement. (Pleck, 1995).

Privileged Minority: I utilize the concept of privileged minority to describe the status that men in psychology possess - simultaneously enjoying societal power and privilege while remaining a statistical minority in the gender composition of the profession. This term has been used in other disciplines (e.g., political science; Bowen, 1983, nursing; Evans, 1997) to suggest the status of being a numerical minority in some context, while retaining the societal power afforded by some dimension of identity (e.g., gender, religion). Graduate Advising Relationship: The graduate advising relationship refers to a relationship on the faculty-student continuum that may be positive or negative, within which guidance related to professional skill development may or may not be provided (Schlosser \& Gelso, 2001).

Advisory Working Alliance: The advisory working alliance is defined as the portion of the advisory relationship that directly reflects the connection between advisor and advisee that is made during work toward common goals (Schlosser \& Gelso, 2001).

Multicultural Awareness: Multicultural awareness refers to the characteristic of multicultural competency that describes a counselor's awareness of his or her own assumptions, values and biases in relation to the dimensions of culture possessed by oneself and others (Sue et al., 1992).

Psychological Distress: I define psychological distress as a participant's score on the Outcome Questionnaire 45.2 (Lambert et al., 2004), with higher scores suggesting greater distress. This measure assesses dimensions related to interpersonal relations, social role functioning, and psychiatric symptom distress. 


\section{CHAPTER II}

\section{Review of Literature}

In this chapter, I begin with a discussion of the graduate training environment in psychology. A brief explanation of GRC theory will follow, with emphasis placed on aspects of the model that may be especially relevant to the study of male psychology graduate students. Thus, a cogent case will be made for employing GRC in this study. Next, I provide an overview of the existing GRC research that has utilized the construct within relevant contexts. I will then discuss several salient training variables and establish the rationale for linking them to the experience of male psychology trainees and GRC.

Finally, I conclude with an overview of this proposed study - GRC within the context of male psychology training.

\section{The Graduate Training Environment in Psychology}

Training tasks and models. Despite particular variances in requirements between training programs, graduate psychology programs share numerous, core similarities. Some common tasks of training include (a) satisfying course requirements, (b) developing and practicing various clinical skills (e.g., practica training), (c) producing original research (e.g., dissertation), and (d) becoming involved in, and socialized to, the professional community. Individual programs espouse training models, which typically fall into one of two camps, namely the Boulder model (Shakow, 1965) and the Vail model (Peterson, 1976). The respective goals of these models vary to the degree in which they favor the training of academic scientists or clinical practitioners. The Boulder model stresses the development of scientist-practitioner skills through the acquisition of both research and clinical competencies (Zachar \& Leong, 2000). In contrast, the Vail model 
aims to produce scholar-practitioners with an emphasis placed on research-informed clinical training.

Common threads of psychological training. Regardless of a programs' training orientation, there are other demands of graduate psychology that exist across doctoral specialty or degree type. Arguably one of the most significant of these demands of contemporary training involves an attention to diversity and multicultural competencies (American Psychological Association, 2003; Tori, \& Ducker, 2004). The inclusion of cultural issues in training burgeoned following a now seminal article by Pederson (1991), which asserted and situated multiculturalism as the "fourth force" in psychology. Multiculturalism has enjoyed an almost ubiquitous inclusion within training programs having been incorporated into coursework, clinical training and research (e.g., Liu et al., 2004; Rogers et al., 1998). The introduction of multiculturalism into the field provided the impetus for psychologists to explore matters of cultural identity in both practice and training alike (Helms \& Cook, 1999). Attending to cultural identity during training is imperative, given the potential for personal similarities and differences to affect students and faculty within interpersonal and intrapersonal domains. Thus, issues of power, privilege and ingroup-outgroup dynamics are especially salient for students, who are charged with cultivating professional relationships with their cohort peers and faculty. It is curious, then, that little is known about the gendered experience of male psychology trainees. Perhaps part of the answer to this inattention to masculinity within the contemporary training environment can begin to be found through the discussion of the gender composition within psychology training programs, past and present. 


\section{The Place of Men in Psychology}

The ever-shifting gender composition of psychology training programs has piqued the attention of researchers (e.g., Pion et al., 1996). Recent national data (American Psychological Association, 2010; 2009a) reveal that, in 2007, approximately $24 \%$ of all doctoral recipients were men; akin to a $23 \%$ male minority among clinical and counseling trainees in 2010 . These statistics compare strikingly against data from 1973, at which point men comprised approximately $80 \%$ of psychologists. In 2003 , that percentage shrank to $50 \%$ (Hart, 2009). We also know that within-program gender differences are not merely circumscribed to individual psychological specialty or degree type. For example, within the specialty of counseling psychology, approximately $65 \%$ of Ph.D. recipients in 2006 were female (American Psychological Association, 2008), with females constituting a slight majority (i.e., 52.5\%) among counseling psychologists. Among counseling psychologists there has been a clear gender shift over the specialty's history - with 84\% being male in 1963 (Yamamoto, 1963) and 80\% in the mid-1980's (Fitzgerald, \& Osipow, 1986; Munley, Pate, \& Duncan, 2008). In sum, these data stress the minimal presence of scholarship around the experiences of men in the field given the combined shifts in gender composition and proliferation of multiculturalism.

Having briefly described the current milieu of graduate psychology training programs, and some of the tasks asked of trainees, I will next further the discussion of gender within the training environment. As stated earlier, insufficient scholarly attention has been devoted to men in psychology practice and training. Furthermore, literature introducing the gendered experience of male psychology graduate students in an academic setting is even more scant (i.e., Wester \& Vogel, 2002). Hence, to continue 
examining the intersection of gender dynamics into psychology training, I shift attention to a model through which the impact of male socialization can be understood, namely GRC.

\section{GRC Theory: Operationally Defined Components}

Despite its steadfast evolution across decades of scholarship (O'Neil, 1981a, 1981b, 1982; 1990; 2008; O'Neil et al., 1986), gender role conflict continues to be defined as "a psychological state in which socialized gender roles produce harmful consequences" (O'Neil et al., 1995, p. 166). GRC is said to occur when "rigid, sexist, or restrictive gender roles, learned during socialization, result in personal restriction, devaluation, or violation of others or self' (O'Neil, 1990, p. 25). As described by O'Neil, (2008) "the ultimate outcome of GRC is the restriction of a person's human potential or a restriction of another person's potential" (p. 363). It is operationally defined by four psychological domains (cognitive, emotional, unconscious, and behavioral), numerous situational contexts, and three personal experiences (devaluation, restriction, violation)."

Furthermore, GRC is expressed behaviorally through four empirically derived patterns/or forms of conflict that represent socially learned and reinforced expectations for masculinity within the United States (O'Neil, 2008). According to O'Neil, these behavioral patterns of GRC are now as the observable and measurable outcomes of Pleck's $(1981,1995)$ conceptual gender role strain model. At their core, these socialized and restrictive patterns and masculine ideologies are rooted in men's fear of femininity. That is, they are related to a strong, negative association with all things stereotypically feminine (e.g., values, behaviors) and reinforced by personal and institutional sexism (O’Neil, 1981a, 1981b). 
The patterns of GRC. As stated above, GRC is characterized by four empirically-derived patterns of behavior: (a) Restrictive Emotionality (RE), (b) Restrictive Affectionate Behavior Between Men (RABBM), (c) Success Power Competition (SPC), and (d) Conflict Between Work and Family Relations (CBWFR) (O’Neil et al., 1986). As defined by O’Neil (2008),

$\mathrm{RE}$ is defined as having restrictions and fears about expressing one's feelings as well as restrictions in finding words to express basic emotions. RABBM represents restrictions in expressing one's feelings and thoughts with other men and difficulty touching other men. The third factor, SPC, describes personal attitudes about success pursued through competition and power. CBWFR reflects experiencing restrictions in balancing work, school, and family relations resulting in health problems, overwork, stress, and a lack of leisure and relaxation. (p. 367) The situational contexts of GRC. When conceptualizing GRC across men's lives, it is imperative to understand its contextual nature - that is, the ability for conflicts to manifest, and cause problems, in myriad situations. O'Neil (1990) organized all possible situational contexts in which GRC may be experienced into four categories: (a) GRC caused by gender role transitions, (b) GRC experienced intrapersonally (within the man), (c) GRC expressed toward others interpersonally, and (d) GRC experienced from others (as cited by O’Neil, 2008, p. 363).

According to O'Neil and Fishman (1992), gender role transitions involve periods or events in a man's gender role development that give rise to an evaluation, alteration or rejection of previously held assumptions regarding his gender role. These transitions can 
prompt the experience of either GRC or positive growth for men. O'Neil \& Egan (1992b) define 30 such transitions (e.g., entering school, becoming a father).

The intrapersonal contextual category, according to O'Neil (2008), "is the private experience of negative emotions and thoughts when experiencing gender role devaluations, restrictions, and violations" (p. 363). For example, a man may have doubts about entering a career as a nurse (which is perceived as violating a male career norm), experience dysphoric feelings (as a result of perceived devaluation of his masculinity) and finally entertain thoughts about pursuing a more traditionally male line of work (which may restrict his occupational options).

The interpersonal contextual categories of GRC (i.e., GRC expressed toward others, GRC experienced from others) assume gender role problems to produce negative consequences between individuals. Specifically, "GRC expressed toward others occurs when men's gender role problems result in devaluing, restricting, or violating someone else. GRC from others occurs when someone devalues, restricts, or violates another person who deviates from or conforms to masculinity ideology and norms" (O'Neil, 2008, p. 363). Thus, a male teacher at school might chide a male student for wearing a pink shirt (i.e., devaluing his appearance as stereotypically feminine) and insist he wear a more gender traditional color (i.e., restricting his future choice of dress). The student perspective of this example, depicts the intrapersonal experience of GRC from others, and describes the way in which another's gender role conflict can result in a man being psychologically affected. The teacher perspective exemplifies GRC expressed toward others interpersonally. 


\section{Male Psychology Students and GRC Theory}

Having reviewed GRC theory and operationalizing its components, attention will now turn to features of GRC that can be viewed as potentially relevant to the study of male psychology graduate students. Research purport that men's psychological difficulties can be theoretically conceptualized using a GRC framework and the related constructs of masculine ideology, masculine norms and male gender role strain (e.g., Good \& Sherrod, 2001; O'Neil, 2008; Pleck, 1981, 1995). Ergo, I find it appropriate to narrow this assertion and conjecture that the GRC framework can offer a conceptual understanding of the experiences of male students within the milieu of psychology training. This assertion is based first and foremost on the belief that gender role socialization processes are arguably similar for all men socialized and indoctrinated within patriarchal and sexist societies (Mintz \& O'Neil, 1990; O'Neil et al., 1986; Wisch \& Mahalik, 1999). It is also assumed that, with such prolific and widespread gender socialization, the potential for gender role conflicts cannot be completely negated by any singular factor (e.g., career choice) within any grouping of males. This includes male psychology trainees who might be assumed to not experience GRC; however, this may be an erroneous assumption.

The intersection of GRC and male trainees. By hypothetically superimposing the various facets of GRC theory onto this subgroup of men, I purport that potential opportunities exist for male psychology doctoral students to manifest GRC. To specify, training experiences could be influenced by conflict stemming from the following: (a) the ever-growing female majority representation in graduate psychology programs, (b) the 
inclusion of gender as an aspect of multiculturalism and personal identity exploration, and (c) certain gender-norm violating qualities present in psychology training.

First, training might be influenced by GRC given the increased female presence within the field of psychology, especially among those recently trained or training, male students may be prone to experience GRC solely due to the female proportion in the environment. This possibility exists according to the founding tenet of GRC theory - the core of men's conflict around their gender role stem from an unconscious and conscious fear of femininity that is promoted through their gender socialization.

The second proposed way that a male trainees training could be influenced vis-àvis the potential for GRC involves gender role transitions. That is, the exploration of one's male gender identity, during multicultural development and training, could prompt a disruption in masculine identity. Thus, in reevaluating or renegotiating one's personal male identity (i.e., a gender role transition), the potential for conflict and/or growth exists.

The final conjecture made in this study is that male students may be susceptible to GRC, as their psychology training experience may involve certain gender violating qualities. Despite research that indicates that psychology is perceived by adults to be a gender-neutral and prestigious profession (i.e., Gottfredson, 1981), some activities which psychologist pursue (e.g., the affectivity of therapeutic process) are at odds with, and may even violate, traditional masculine value systems and behavior norms (Kiselica, 2001; Wester et al., 2002). Thus, by extension, men receiving training to function as a future psychologist may experience (a) internal GRC around these behaviors/values, and/or (b) external GRC as a result of others devaluations of their academic and occupational pursuits. In addition, Gottfredson's aforementioned assertion that the perception of 
psychology is gender-neutral should be considered cautiously in light of the gender shift that has taken place since the date of that study. Essentially, more current research is needed on the contemporary perception of psychology with regards to sex role and prestige levels.

Having considered these hypothetical intersections of GRC theory and the training of male psychology graduate students, a caveat is warranted. The aboveconjectured grounds for GRC to exist during training are offered in the absence of sufficient research. Thus, while GRC theory does lend support to the aforementioned speculations, how or if GRC manifests among male trainees has not been yet demonstrated empirically. Furthermore, the personal congruence between a man, the field of psychology, and his occupational role stem from, above all else, an individualized set of psychological and social qualities. As stated by Gottfredson (1997), adults typically "have identified the occupational roles that would allow them to project what they consider to be a suitable image of themselves" (p. 425). Hence, it is also reasonable to assume that not all male psychology doctoral students will experience GRC or its posited manifestations (e.g., gender role devaluations, gender role violations) within the training environment.

The utility of GRC in this study. Although GRC is merely one model which examines the effects of traditional masculinity, its utilization may also be viewed as a respectable first step in the study of male psychology students. Given the relative dearth of research on this group of men, empirically evaluating this population against traditional male norms and behaviors is crucial to developing this line of scholarship. As GRC fits within a deficit model of manhood (e.g., Doherty, 1991), the construct will 
inherently not cast light on many positivistic aspects of the gendered experience of these men. However, employing a deficit model is prudent - as the potential exists for the deleterious aspects of male socialization to negatively affect the professional training of these men, and by extension, those they serve. Having offered a theoretical relationship between aspects of the GRC model and male psychology trainees, as well as a rationale for utilizing this model, a summary of relevant GRC research follows.

\section{Extant Research on GRC in Relevant Contexts}

Considering the decades of attention to GRC and the voluminous scholarship that has accrued over 230 studies (see O'Neil, 2008), the mechanisms of GRC within the psychotherapeutic process have been gone relatively underexplored. O'Neil (2008) commented that this trend relates to and reflects the larger lack of priority for scholarship examining of how to help men in therapy. Mellinger and Liu (2006) found support for this assertion in a survey of counseling psychology doctoral program faculty.

Specifically, these researchers found that training practices (e.g., faculty involvement and interest) in the study of men were few and limited. Despite this trend, psychologists (e.g., Mahalik, Good, \& Englar-Carlson, 2003; Rochlen, 2005) continue to reference the costs of male socialization (e.g., GRC) as a relevant and necessary consideration when working with men in treatment. Of the explicit literature that has investigated GRC in a therapeutic context, four studies (i.e., Hayes, 1985; Wester \& Vogel, 2002; Wester et al., 2004; Wisch \& Mahalik, 1999) prove the most germane to the aims of this present research as they involve therapists and therapists in training. In addition to a review of these four studies, additional findings will be reported that are apropos to GRC in the 
therapeutic context. These studies will be divided into two sections: (a) attitudes toward help-seeking, and (b) vocational choice.

Therapists' GRC. The ways in which GRC affects therapists' clinical attitudes and judgments have been explored in two studies. Wisch and Mahalik (1999) studied male therapists' attitudes of male clients, and found higher SPC and RABBM to correlate with less empathy towards and comfort with male clients. They also found that male therapists with lower RABBM reported greater comfort seeing, and better prognosis for, gay clients. Findings from Hayes (1985) indicate that therapists with a higher RABBM pattern had less comfort in working with male clients, as well as less empathy with and a more negative evaluation of nontraditional (e.g., overtly emotional) male clients. These two studies demonstrate how GRC affects male therapists' attitudes towards male clients, with especially negative judgments, thoughts and feelings towards clients who are nontraditional or gay males.

The role of GRC in the training of psychologists has been addressed in two papers (Wester \& Vogel, 2002; Wester et al., 2004). In a critical conceptual contribution, Wester and Vogel (2002) championed the need for psychologists to understand and examine the role of GRC on male psychologists' clinical performance, self-efficacy and training. They offered several suggestions to aid training programs in being supportive in their male students' gender role development process. These suggestions included the need for training programs to "affirm their support of their male students' gender role developmental process by providing faculty, staff, and students with current theory and research on men's issues," (p. 374), and for faculty to "make an effort to include a masculine perspective in their work, value the positive aspects of masculinity, discourage 
the negative aspects of masculinity, and assist their students in combating the negative or stereotypical reactions of those around them" (p.374). More recently, another conceptual article by MacKinnon, et al. (2011) has built upon these suggestions, expressing that feminist-informed theories be applied to the supervision of males within the mental health field so as to develop trainings tailored to gender dynamics.

In an empirical study of male psychology interns in a supervisory relationship, Wester and colleagues (2004) found that increased GRC (i.e., reactive emotionality) negatively affected both counseling self-efficacy and the supervisory working alliance. The results of this study begin to expose some of the ways in which GRC can negatively affect the professional development of male psychology students - in this case, within the sphere of clinical training. Next is a brief summary of findings of GRC studies that provide ancillary relevance for the current study, despite not sampling men in psychology.

GRC and attitudes toward help-seeking. Although we did not know how men in psychology compare to other male samples regarding conflict with traditional gender roles, some initial conjecture was made with support from findings of GRC and attitudes towards help seeking. The relevance of these studies pertains to the aforementioned notion that many aspects of help-seeking are considered antithetical to traditionally male values and norms. Psychotherapy, in particular, is especially alien to those who endorse traditional masculine ideologies because of (a) the exposure, exploration and discussion of personal problems, (b) the encouragement of affective expression, and (c) the reliance on another to facilitate the process. Furthermore, the process of therapy is arguably more congruent with a traditionally female affective style than with a traditionally male 
affective style (Kiselica, 2001; Wester et al., 2002). Thus, as GRC is theoretically rooted in the fear of femininity (O'Neil, 1981a, 1981b), it is not surprising that researchers have explored the relationship between GRC and help-seeking attitudes, behaviors and preferences. In total, 19 studies have looked at these relationships - with 18 studies finding a positive relationship between GRC and negative attitudes towards seeking psychological help (see O'Neil, 2008 for a complete review). The aggregate results from these studies further buttress the preliminary contention that males, who pursue careers (e.g., psychology) that value the provision or seeking of help, may have certain nontraditional masculinities. Hence, their personal experiences of GRC should be subjected to empirical scrutiny so as to better explain the qualities of a psychology career to the men who seek it.

GRC and vocational choice. To date, few studies have explored how GRC relates to male career development and career choice (O’Neil, 2008). Despite its infancy, this line of research has demonstrated that men with greater GRC are often career traditional men and that, by extension, GRC is predictive of traditional career choice (Dodson \& Borders, 2006; Jome \& Tokar, 1997; Tokar \& Jome, 1998). Other studies (Rochlen, Blazina, \& Raghunathan, 2002; Rochlen \& O'Brien, 2002) found that men with higher GRC are more stigmatizing of career counseling and less interested in assistance during periods of career indecision.

Although the study of GRC and vocation is not directly pertinent to the current study, these findings provide initial evidence that men in psychology doctoral programs may have lower GRC by virtue of their pursuit of a non-traditionally male career and subsequent deviation from tradition male norms (Dodson \& Borders, 2006; Jome \& 
Tokar, 1997; Tokar \& Jome, 1998). While the formal characterization of the profession of psychology is unsettled vis-à-vis its perceived gender traditionality, the marked feminization of the field and perceptions of some researchers assert that the profession does not have a distinctly masculine numerical majority (American Psychological Association, 2010; Hart, 2009) or traditionally male task orientation (e.g., Kiselica, 2001 ; Tokar \& Jome, 1998; Wester et al., 2002). Akin to the aforementioned discussion of helpseeking attitudes, these results demonstrate another implicit incongruence between men who exhibit certain traditionally male behaviors and those who do not. However, the above results are somewhat inconsistent with those put forth by Wisch and Mahalik (1999) who found that male therapists (mostly doctoral-level practicing an average of 22.04 years) did not significantly differ from prior male sample on patterns of SPC and CBWFR. These researchers suggest that because "therapists are highly career and family oriented, it is not surprising that they struggle with many of the same gender role conflict issues in these areas as do other men" (p.57). Again, further exploration of patterns of GRC and men in psychology are needed in order to begin to replace conjecture with empirical data.

In sum, the existent studies of career choice and GRC again express an area in which male psychologists may differ from more traditionally oriented males. First, in that, some activities of a psychologist (e.g., psychotherapy) may be perceived as incongruent with a transitional masculine ideology. Second, that a major value of psychology (i.e., counseling psychology) is vocational and career development (Gelso \& Fretz, 2001). Researchers have found men higher in GRC to be more likely to reject the formal vocational guidance provided by psychologists and counselors (Rochlen, et al., 
2002; Rochlen \& O'Brien, 2002). However, without empirical study of males in psychology, it is inappropriate to generalize these limited findings to this population. In citing these findings and purporting hypothetical relationships between career choice to male psychology students and GRC, the study aim was to prompt future researchers to consider this population especially vis-à-vis the aforementioned recent demographic shifts in the profession.

\section{Related Training Experience and Outcome Variables}

Having offered a review of relevant GRC research, I will now establish a link between these past findings and several variables I purport to be of particular interest to the current study. One critical aspect of the graduate psychology training experience is the relationships students build with their faculty. These relationships are vital to students' successful navigation of programmatic requirements and professional development (Schlosser \& Gelso, 2001; 2005). Taking into account the interpersonal consequences of GRC the qualities of such student-faculty relationships logically warrant exploration along these lines. Thus, I begin with a review of one form of student-faculty relationship - specifically the advisory relationship.

\section{The Advisory Relationship}

Advising defined. Defining the advisory relationship begins with the understanding that advising is one type of student-faculty relationship. Akin to other such relationships, most notably mentoring, the advising relationship is positioned on a continuum of student-faculty relationships. Schlosser and Foley (2008) have conceptualized this continuum as being positive and helpful at one end and negative and harmful at the other. The aforementioned mentoring relationship lies at the extremely 
positive end. Mentoring is believed to be an inherently positive and idealized relationship, marked by increased mutuality, reciprocity and intimacy, and continuing after a student graduates (Johnson \& Huwe, 2002). However, the advising relationship can be situated anywhere on the continuum of student-faculty relationships (Schlosser \& Gelso, 2001; 2005). Furthermore, its position on the continuum may shift throughout the duration of the relationship. This versatile range in relationship quality mirrors the breadth of function which advising serves. Schlosser and Gelso (2001) defined an advisor as "the faculty member who has the greatest responsibility for helping guide the advisee through the graduate program" (p. 158). Advising typically involves the technical guidance and facilitation of a student's progress throughout the graduate program (Schlosser \& Gelso, 2001; 2005). However, scholars have more recently included a variety of other potential functions (e.g., career guidance, networking, clinical supervision) within the multifaceted charge of the advisor (Knox, Schlosser, Pruitt, \& Hill, 2006; Schlosser \& Foley; Schlosser, Knox, Moskovitz, \& Hill, 2003; Schlosser \& Kahn, 2007).

The advising relationships is the primary focus in the current study as they are arguably the most prevalent and inclusive student-faculty relationships within the graduate training environment (Schlosser \& Gelso, 2001; 2005). That is, advising provides the largest range of both student-relationship quality and functions and subsequently offers the most applicability and relevance for male psychology trainees. I next introduce the research on the advising relationship in order to further emphasize the relevance of the advising construct to men in doctoral training. 
Existing advising research. An extensive literature review on the advising relationship produced only six empirical studies - suggesting that research in this area is in its infancy. In a first step to measure this construct, Schlosser and Gelso focused on the advisory working alliance and constructed the Advisory Working Alliance Inventory (AWAI). This measure was validated with both student (AWAI-S; 2001) and advisor (AWAI-A; 2005) versions. This initial scholarship demonstrated the relevance and importance of the advisory working alliance for both students and faculty. Furthermore, it identified three subscales (i.e., Rapport, Apprenticeship, Identification-Individuation) of the advisory working alliance, which describes distinct components of the relationship from the advisee perspective. Such components encapsulate both the emotional bond and working relationship that exists within the advisory dyad. Analogously, from the advisor perspective, three subscales emerged (i.e., Rapport, Apprenticeship, Task Focus) to describe the nature of the relationship.

For students, findings indicate the advisory working alliance to be positively correlated with such relevant training constructs as: (a) research self-efficacy, (b) attitude toward research, and (c) perceptions of the advisor's social influence (i.e., expertness, attractiveness, and trustworthiness) (Schlosser \& Gelso, 2001). In addition, results suggest that certain periods of the time within the length of the advisory relationship correlate to advisees' attitudes towards research. It is possible that during these periods of time, the advisory relationship and advisor may have greater influence of the development of the advisees' efficacy in this area. Thus, it can be argued that "the initiation and development of a working alliance with one's advisor is an important 
developmental task for the graduate student to accomplish" (Schlosser \& Gelso, 2001, p. 165).

With regard to advisors, findings from Schlosser and Gelso (2005) show the advisory working alliance to be positively related to advisors' (a) satisfaction with the advisory relationship, (b) perceived benefits from advising, and (c) ratings of advisoradvisee meeting quality (i.e., smoothness and positivity), (d) perception of the advisee's research self-efficacy, and (e) perception of the advisee's interest in science and practice. Furthermore, the advisory working alliance was demonstrated to be negatively related to the costs associated with advising (e.g., time commitment). Hence, these findings suggest that a positive advisory relationship, from the advisor's perspective, involves advising students who possess greater research self-efficacy, an interest in science and practice, who contribute to meetings characterized by smoothness and positivity and who do not produce significant advisory costs.

Two qualitative studies furthered this line of research investigating the complementary sides of the advisory dyad; the advisee's perspective of the advising relationship (Schlosser et al., 2003) and the advisor's perceptions (Knox et al., 2006). Results from the advisee study illustrate distinct differences between students who felt satisfied with their advisory relationship and those who did not across interpersonal and instructional components of the relationship. Satisfied students reported feeling respected, supported and encouraged by their advisors, while those less satisfied expressed feeling unimportant, ignored and neglected. With regards to instructional components of the advisory relationship, satisfied advisees as compared to their dissatisfied counterparts, reported (a) more frequent meetings with the advisor, (b) aid in 
navigating aspects of the training program aside from research competency (e.g., comprehensive exams), (c) focus and attention on career guidance, and (d) increased professional development (e.g., advisor encouraging participation in professional activities and aiding in social networking).

In the advisor study (Knox, et al., 2006), faculty depicted their role as advisor "as one of supporting and advocating for advisees as they navigated and completed their doctoral program" (p. 503). Furthermore, these advisors described positive advisory relationships are being composed of (a) a lack of conflict or power negotiation, (b) mutual respect, (c) open communication, and (d) positive personal and professional traits (e.g., motivated, fun, reliable). On the other hand, more negative or difficult advisory relationships were portrayed as having (a) problems in communication, (b) periods of conflict avoidance, (c) negative personal and professional traits (e.g., rigid, lazy, presumptuous), and (c) a lack of respect between advisor and advisee. Turning away from interpersonal characteristics towards instrumental components, difficult advisory relationships were also marked by advisee difficulty with research competency (e.g., disinterest in research, extensive need for assistance and revision). Also, advisors in this study reported that career path similarity contributed to more positive effects within good advisory relationships. Such similarity between advisor and advisee was described as increasing initial cohesion within the dyad vis-à-vis mutual respect.

Following these initial qualitative and quantitative studies on advising, Schlosser and Kahn (2007) explored advisor-advisee dyads in counseling psychology doctoral programs. The aim of this investigation was to obtain a fuller understanding of the advisory process, as the advisory working alliance is intuitively a dyadic process. The 
first goal of this study was to assess the degree of agreement, between advisor and advisee, on the quality of their (a) advisory working alliance, (b) advising meetings, (c) interest in scientist and practitioner activities, and (d) assessment of the advisee's research competence. Secondly, Schlosser and Kahn examined the influence of interest similarity (i.e., in science and practice) within the dyad on the advisory relationship and relevant outcomes. The final goal of this study was to determine what, if any, associations exist between advisor and advisee ratings of the advisory working alliance and both, aspects of the advisor's experience and advisees' training outcomes.

First, findings suggest a moderate amount of agreement between advisors and advisees ratings on a number of advisory components (i.e., their advisory working alliance, the smoothness of advisory meetings, and the advisee's research competency) and by extension, their perceptions of the relationship (Schlosser \& Kahn, 2007). Additionally, results suggest that similarity of interests between the advisor and advisee is not significant, and thus neither affected (a) the quality of the advising relationship, or (b) advisor attitudes about advising the student. Finally, findings indicate that advisees' ratings of the advisory working alliance were positively correlated to their view of their own of research self-efficacy. The advisors' ratings of the advisory working alliance were correlated to (a) the smoothness and positivity of advisory interactions, and (b) the costs and benefits of advising, in theoretically consistent ways.

As stated earlier, psychologists have not answered the call made by several researchers (i.e., Schlosser \& Gelso, 2001, 2005) to empirically examine the ways in which dimensions of personal identity (e.g., race, gender, religion, sexual orientation) affect the development and maintenance of the advisory working alliance. In a valued 
first step to draw additional scholarly attention to this gap in the literature, Schlosser and Foley (2008) offered a conceptual examination of how the faculty-student relationships (e.g., mentoring, advising) in graduate psychology training are influenced by dimensions of personal identity and cultural dynamics. In this article, Schlosser and Foley addressed several probable issues that could arise when cultural dynamics (i.e., race and ethnicity, gender and sexuality, age, religion, ability status) intersect with student-faculty relationships. These researchers remind us that, although a solid foundation into the advisory relationship has been laid, a fuller picture of what makes advising, and perhaps other student-faculty relationships, work, remains largely absent. In the first empirical attempt to include aspects of cultural identity into advisory research, Rice et al. (2009) studied a diverse sample of international students (e.g., nationality, discipline of study). In addition to supporting the utility of the AWAI-S for use with a sample of international students, these researchers also (a) found lower ratings of advisory alliance (i.e., Rapport, Identification-Individuation), and (b) suggested cultural differences to be a salient factor contributing to dissatisfaction/satisfaction within the advisory relationship. Thus, these scholars' (i.e., Schlosser and Foley, Rice et al.) contributions are most germane to the aims of the present study, in that, they highlight an important need in advising research namely, continued attention to cultural diversity and dynamics of personal identity.

The aim of the present study is to address the workings of advisory relationship by employing a multicultural lens. Specifically, the exploration of the advisory working alliance and traditional restrictive male norms (i.e., GRC) will begin to delineate the influence of gender on male students' perspectives of their advisement. Perhaps it is the case that certain constraints of traditional masculinity (e.g., interpersonal costs of 
restrictive emotionality) adversely affect the advisory relationship - thereby producing further training consequences for the student. This scenario represents one area of graduate training where GRC may be especially deleterious. However, the potential for conflict around one's gender role to affect professional training is hardly circumscribed to the advisory relationship. Considering the demands of the graduate psychology training environment outlined earlier in this chapter, the focus now turns to how some forms of psychological distress can more globally impact the experience and development of male trainees.

\section{Psychological Distress}

The opportunity for GRC to impact the training of male psychology students is arguably most diverse when such conflict manifests in psychological distress (e.g., anxiety, depression). Such distress can obviously impair functioning and competency as a psychologist in training. A sizeable amount of empirical evidence exists to implicate patterns of GRC in men's experience of psychological distress (see O'Neil, 2008 for a complete review). A convincing number of these studies have implicated relationships between depression and patterns of restrictive gender roles across diverse samples of men. According to O'Neil (2008),

The studies provide substantial evidence that men's restrictive gender roles relate to men's depression. Men who restrict their feelings, restrict their affections toward other men, and struggle with work and family conflicts report significantly greater depression. Likewise, restrictive attitudes toward success through competition and control significantly predicted male depression (p. 383). 
Past researchers have pointed to other signs of psychological distress in exploring the negative consequences of restrictive male gender roles. Specifically, some (e.g., Sharpe \& Heppner, 1991; Sharpe, Heppner \& Dixon, 1995) have found patterns of GRC to be negatively correlated with psychological well-being. Such findings are empirical validation of the O'Neil's (1990) assertion that gender role restrictions contribute to the opposite of well-being, as they create negative psychological consequences internal and external to men. In addition to depression and well-being, O'Neil (2008) adds that, "the overall evidence indicates that GRC is significantly related to men's anxieties" (p. 384). Thus, to extrapolate to the graduate training environment, the potential exists for the certain realities (e.g., female student majority, focus on expressed emotion) to challenge or even debilitate students with masculine role issues and vulnerability to psychological distress. For all graduate psychology students, the rigors and duration training can be mollified, at least in part, by moments of pride over periodic accomplishments (e.g., a positive clinical session, presenting at a conference, completing first externship).

However, for men in a state of GRC during training, such moments are likely diminished or never realized given concerns over their masculine identity.

When this distress is contextualized among psychology trainees, it is logical to assume such symptomotology to manifest and interfere across a multitude of settings (e.g., clinical, classroom, social) and in a plethora of tasks (e.g., research proficiency, professional involvement, coursework, therapy), throughout the duration of training. Such potential consequences are especially significant when considering the established body of literature around educational gatekeeping and clinical competencies in graduate student training (e.g., Forrest, Elman, Gizara, \& Vacha-Haase, 1999; Kaslow, 2004; 
Wester, Christianson, Fouad, \& Santiago-Rivera, 2008). In fact, Johnson and Campbell (2002) described global competency for practicing psychology as involving "character traits [in addition to] personal and emotional fitness requirements" (p. 46). Hence, the absence of these required qualities leads to diminished competency and impairment during training. Forrest et al. commented that gender differences in trainee impairment and dismissal have yet to be established and called for future researchers to explore the role of individual differences (e.g., gender, race) on impairment during training. However, to date, a review of scholarship in this area finds little guidance into how issues of professional training competencies are related specifically to psychological distress among male students.

Thus, building upon what is known about GRC and psychological distress among men, the application of these principles to male students in psychology training programs is necessary and warranted. Findings in this area have implications for: (a) male doctoral psychology students - with regard to training and remediation, and (b) graduate psychology training programs - pertaining to programmatic decisions around gatekeeping and clinical competency. Lastly, multicultural competency and GRC are introduced and discussed, as they pertain to the professional training experience of men in psychology. Given its aforementioned central presence and value in graduate training, consideration is given to the potential ways in which male psychology students experience matters of cultural identity and diversity to be an integral component to the current study. Of specific concern are the potentially negative consequences of the male gender role vis-à-vis the acquisition and development of competencies in this area. This point is attended to in the following section. 


\section{Multicultural Awareness}

A budding line of research (see O'Neil, 2008 for a complete review) exists on the relationships between patterns of GRC and biased attitudes towards women and other marginalized groups (e.g., racial/ethnic minorities, lesbian, bisexual, gay, transgendered persons). Existing research has found GRC and its patterns to be significantly related to traditional attitudes and stereotyped thinking towards women (e.g., Blazina \& Watkins, 2000; Robinson \& Schwartz, 2004). Other, more limited research has found increased patterns of GRC, namely, RABBM and SPC, to correlate with negative attitudes towards African Americans (Robinson \& Schwartz) among White males. Furthermore, researchers (e.g., Wilkinson, 2004) have shown patterns of GRC to relate to homophobic and anti-gay attitudes among men. In sum, these studies evidence the role GRC in biased and stereotypically negative attitudes towards women, People of Color (i.e., African Americans), and LGBT people.

Thus, the potential for patterns of GRC to manifest in biased and stereotypically negative attitudes towards women, People of Color and LGBT individuals is clearly at odds with professional and ethical standards for competency as a psychologist. Among male psychology trainees, this potential consequence of GRC can stymie an integral goal of psychological training - namely, the development of multicultural competence. This potentially negative training outcome becomes exacerbated in light of recent findings that suggest a strong relationship between multicultural and general competencies for clinicians (Constantine, 2002; Fuertes \& Brobst, 2002). Within graduate training programs, the model of multicultural competency most often utilized is the Sue, Arredondo, and McDavis (1992) awareness, knowledge and skills paradigm (Pope-Davis, 
Coleman, Liu, \& Toporek, 2003). This tripartite framework emphasizes not only the procurement of abilities to work with clients from culturally diverse or underrepresented groups, but also a focus on the psychologist's self-understanding.

Historically, however, the pursuit of multicultural competence was limited to People of Color vis-à-vis the contextual understanding of their sociopolitical histories, and lived experiences (Liu \& Pope-Davis, 2003). Early multicultural scholars believed that the exploration of People of Color deserved primacy and was well-warranted given the scholarly neglect suffered by these groups for living in a male and White dominated milieu. As scholarship around multiculturalism expanded, so too did the diversity of groups studied. A broader focus on contextualization, culture and socialization logically paved the way for the exploration of hegemonic experiences, namely Whiteness and masculinity (Liu, 2005; Sue \& Sue, 2003).

As a result of multiculturalism's increased attendance to majority culture, the study of societal privilege and power, as ubiquitous hegemonic characteristics, has emerged. As masculinity is steeped in power and privilege, such a focus has particular relevance for the present study. Male psychology trainees hold societal power while simultaneously remaining a demographic minority within the training environment. This unique position prompts an examination into how these gendered power dynamics affect the experience and training of male psychology graduate students. Given the aforementioned findings regarding GRC and biases, it would seem logical to posit that conflict around male students GRC activates male privilege and power. Perhaps it is the case that characteristics of doctoral psychology programs ignite dimensions of socialized 
masculine identity (e.g., GRC, power, privilege, oppression) that subsequently affect professional and personal growth around multicultural awareness.

In fact, literature pertaining to multicultural competency is shifting towards the study of privilege and oppression within the training environment. These researchers (e.g., Hays, Dean, \& Chang, 2007), seek to demonstrate the ways in which student's perceptions of privilege and oppression within their academic and clinical settings. Findings from certain studies (e.g., Constantine, 2002) reveal a significant connection between the clinician's awareness of privilege and oppression and their general multicultural competency. Hence, this recent line of research suggests that increasing clinician's or trainee's awareness around issues of privilege may assist in the growth of multicultural competencies (Hays, 2008).

This study aims to serve as an important first step in measuring the relationship between masculinity and multicultural adeptness among male psychology doctoral students. Specifically, I chose to focus on the awareness dimension of the Sue et al. (1992) multicultural competency paradigm. Holding the assumption and belief that an awareness of others and oneself as cultural beings predicates the acquisition of both knowledge and skills warrants attention. Sue et al., (1992) largely conceptualizes and assesses culture as a matter of ethnicity and race. Hence, awareness, as it pertains to selfreported competencies with other salient dimensions of identity (e.g., religion, gender, sexual orientation) can only be extrapolated. Furthermore, a nuance of masculinity, namely, awareness of power and privilege, is not measurable by contemporary instrumentation. A recent call by Hays (2008) proposes that researchers develop an instrument that empirically assesses clinician's “awareness of privilege and oppression 
across cultural identities" (p. 99). Thus, in considering the possible constructs related to multicultural competencies, I believe awareness to be the most relevant and potentially fruitful for the scope and aims of the current study.

Despite this slight limitation around instrumentation, this line of empirical inquiry could also serve as a proxy to generate beginning hypotheses for how male privilege operates among students within the training environment. That is, perhaps diminished multicultural awareness may be a function of increased defensiveness (e.g., activated power and privilege) among male trainees. The consequences of poor awareness into aspects of cultural identity are great. Yet, such costs are potentially amplified when the clinician or trainee carries societal power (e.g., male, White). For the psychologist in training, minimal awareness of privileged status and/or of representing privilege and oppression to others may be interpersonally damaging within both clinical (Ancis \& Szymanski, 2001) and academic settings. To return focus onto masculinity, one example of a consequence of minimal awareness of others and self as cultural beings is the ensuing reliance on stereotypes.

\section{Conclusion}

This chapter provides an overview of the graduate training environment in psychology. Next, the theory of GRC was described and emphasized as a construct with a long history of empirical attention and support. However, the existing research on GRC has largely ignored its application to men providing, or training to provide therapeutic services. In fact, only three studies (Hayes, 1985; Wisch \& Mahalik, 1999; Wester et al., 2004) have attended to GRC among male practitioners and graduate students in clinical settings. These studies found negative consequences of GRC on clinical practice, namely 
more negative interactions (i.e., poorer prognosis, less empathy) toward nontraditional male clients (Hayes; Wisch \& Mahalik) and poorer clinical self-efficacy and supervisory working alliance (Wester et al.). These studies exposed an area for growth within GRC and clinical training literature. An important next step is to explore GRC among males in graduate psychology training programs, as past literature and theory (e.g., Mahalik et al., 2003; O’Neil, 2008; O’Neil \& Egan, 1992a, 1992b; O’Neil et al., 1995; Wester \& Vogel, 2002) suggests that this environment would be apt for the experience of GRC.

Both GRC theory and ensuing empirical findings have provided the logic and rationale to begin the examination of GRC among male doctoral psychology trainees. It has been well documented that GRC can negatively impact a man across intrapersonal, interpersonal and therapeutic domains (O’Neil, 2008). As described in this chapter, increased levels of GRC patterns have been empirically linked to many deleterious experiences (e.g., biased and stereotypic attitudes, depression, anxiety). These experiences are especially salient and consequential when juxtaposed against the demands of graduate psychology training. Within the academic training environment (a) the advisory working alliance, (b) psychological distress, and (c) the acquisition of multicultural awareness, all deserve empirical inquiry vis-à-vis GRC. Hence, this chapter supports the value and significance of the current study, namely to examine GRC within the experience of male doctoral psychology students. Such inquiry will inform future research and practice, so that training needs can address the consequences of gender conflicts among men in psychology and, by extension, those they serve. 


\section{CHAPTER III}

\section{Methodology}

This chapter includes details about the sample used in this study. Also included are descriptions of the measures that were used, including their psychometric properties. Finally, the statistical design of the study and participant recruitment will be discussed.

\section{Participants}

Participants consisted of male doctoral psychology students who identified as being currently been enrolled in APA accredited counseling or clinical doctoral programs.

\section{Power Analysis}

A priori power analyses were run using $\mathrm{G}^{*}$ Power 3 software (Faul, Erdfelder, Lang, \& Buchner, 2007). The first analyses used in this study, namely, one-sample $t$ test, required a sample size of 34 ; with an alpha of .05 , and power set at .80 . Adjusting the alpha level to .01 , due to the number of $t$ tests run, required a sample of 51 with the same power setting. The second analysis used in this study was a multiple regression. Results of this power analysis, with an alpha .05 and power set at .80 , indicate that 85 participants are required. Adjusting the alpha level to .017 (due to multiple regressions) required a sample of 108 with the same power setting. Finally, additional power analyses revealed that sample sizes of 32 and 30 were required to complete two exploratory MANOVAs with power set at .80 and an alpha of .05 .

\section{Measures}

The measures used in this study were the Gender Role Conflict Scale (GRCS; O’Neil, et al., 1986), the Advisory Working Alliance Index- Student Version (AWAI-S; 
Schlosser \& Gelso, 2001), the Multicultural Awareness, Knowledge, and Skills SurveyCounselor Edition-Revised (MAKSS-CE-R; Kim, Cartwright, Asay, \& D’Andrea, 2003), the Outcome Questionnaire (OQ-45.2; Lambert et al., 1996, 2004), and a demographic questionnaire.

Gender Role Conflict Scale. The GRCS (a 37-item, 6 point Likert-type scale with $\mathrm{I}=$ strongly disagree to $6=$ strongly agree) was used to assess male trainees' level of gender role conflict. Four factors emerged during its development, which formed the four subscales of the GRCS (i.e., Success, Power, Competition (SPC), Restrictive Emotionality (RE), Restrictive and Affectionate Behavior Between Men (RABBM), and Conflict Between Work and Family Relations (CBWFR).

Since its creation, many researchers have sought to study and validate the psychometric properties of the GRCS. In total, 22 independent factor analyses (e.g., O’Neil et al., 1986; Moradi, Tokar, Schaub, Jome, \& Serna, 2000) have been completed and have shown the scale to have construct validity among U.S. college students (O'Neil, 2008). Original Cronbach's alphas for each subscale were: SPA (.85), RE (.82), RABBM (.83), and CBWFR (.75). In addition, factor intercorrelations have been shown to be moderate, ranging from .35 to .68 (Moradi et al.). Thus, suggesting that although the factors are related to each other, they remain independently distinct. The four factor structure of the GRCS, as originally developed by O'Neil and his colleagues, has been further supported through confirmatory factor analysis in several studies (e.g., Moradi et al.; see O’Neil, 2008 for a complete review).

Given its decades of use, many researchers have studied and assessed other psychometric properties of the GRCS. The internal consistencies of the GRCS for college 
men have ranged from .70 to .89 across many studies (e.g., O'Neil et al., 1986; Good et al., 1995). Furthermore, internal consistency tests for more diverse groups have shown similar acceptable to good reliabilities $(.71-.91)$. Test-retest reliabilities have been demonstrated over a 1 month period with ranges of .72 and .86 across each of the measure's four factors (O'Neil et al.). Regarding convergent validity, the GRCS has been assessed alongside other masculinity measures (e.g., Conformity to Masculine Norm Inventory; Mahalik, Locke, et al., 2003) demonstrating significant correlation (median $r s$ ranging between .32 and .49 ). These correlations imply the GRCS to be similar to other instruments of masculinity, but distinct in the specific construct measured. Divergent validity has been evidenced by the negative correlation of three factors of the GRCS (i.e., SPC, RE and RABBM) to a measure of sex role egalitarianism (Englar-Carlson \& Vandiver, 2002).

Advisory Working Alliance Index- Student Version. The AWAI-S (a 30-item, 5 point Likert-type scale with $(1=$ very strongly disagree to $5=$ very strongly agree $)$ was used to assess male trainees' perceptions of the working alliance within their advisory relationships. There are three subscales for the AWAI-S (Rapport, Apprenticeship and Identification-Individuation), derived from initial factor extraction and development. Initial psychometric support for the AWAI-S was found by Schlosser and Gelso (2001) for use with students in graduate psychology programs. Specifically, in two, separate studies, these researchers estimated the measure to have sound internal consistency, testretest reliability as well as construct and convergent validities.

Internal consistencies were found to be satisfactory. Cronbach's alphas for the AWAI-S and each subscale were: AWAI-S Total (.95), Rapport (.93), Apprenticeship 
(.91), and Identification-Individuation (.77). Findings also demonstrate the stability of the AWAI-S and its subscales to be satisfactory over a two-week period with estimates ranging from .75 to .92 . Initial construct validity was found as a result of significant relationships between the AWAI-S and related constructs (i.e., research self-efficacy, attitudes towards research). Convergent validity was demonstrated by the positive, moderate to high, relationships between the subscales of the AWAI-S and the perceived expertness, attractiveness, and trustworthiness of the advisor (Schlosser \& Gelso, 2001).

\section{Multicultural Awareness, Knowledge, and Skills Survey- Counselor Edition-}

Revised. The MAKSS-CE-R (a 33-item, 4 point Likert-type scale with three different response definitions: $1=$ very limited to $4=$ very aware; $1=$ very limited to $4=$ very good; $1=$ strongly disagree to $4=$ strongly agree) was used to assess male trainees' level of multicultural competence. This measure (Kim et al., 2003) is a revision of the MAKSSCE (D'Andrea, Daniels, \& Heck, 1991) and was originally created and validated in two studies. Across these two samples, the revised measure demonstrated good reliability among graduate counselor education students.

Internal consistencies were found to be adequate. Cronbach's alphas for the MAKSS-CE-R and each subscale were: MAKSS-CE-R Total (.81), Awareness-R (.80), Knowledge-R (.87), and Skills-R (.85). Construct validity was demonstrated through similar, yet distinct scores between the MAKSS-CE-R and other measures of multicultural competency (i.e., MCKAS; Ponterotto, Gretchen, Utsey, Rieger, \& Austin, 2002; MCI; Sodowsky, Taffe, Gutkin, \& Wise, 1994). Discriminate validity was demonstrated by an association between scores on the MAKSS-CE-R and a measure of self-esteem - suggesting that the MAKSS-CE-R is not a measure of positive self-regard. 
Criterion-related validity was shown by higher scores attained on the MAKSS-CE-R by those students who had taken at least one course in multicultural competence, as compared to those who had not. Results also indicate that the MAKSS-CE-R accounted for roughly a third of the variance $(29.80 \%)$ that the original, 60-item MAKSS-CE had accounted for. Hence, this limitation suggests that the MAKSS-CE-R does not capture an exhaustive measurement of multicultural knowledge, awareness and skill (Kim et al., 2003).

In the present study, only the Awareness subscale of the MAKSS-CE-R was used. This 10-item subscale was used to assess male trainees' level of multicultural competency awareness. As compared to the original MAKSS-CE Awareness subscale, the Awareness subscale yielded an improved internal consistency (.80) after omitting more than half of the original items. Regarding construct validity, there was a positive correlation found between the Awareness and Multicultural Awareness (MCI-A) subscales. Interestingly, regarding social desirability, the Awareness subscale demonstrated an inverse relationship with a measure of social desirability (i.e., $8 \%$ shared variance with the Social Desirability Scale (SDS-XX). Therefore, participants who attempted to complete the Awareness subscale in a socially desirable manner attained a lower score than participants without such an approach. This evidence suggests that the common criticism of self-report measures being susceptible to social desirability, and thus inflating one's self-reported multicultural competence, does not apply to the Awareness subscale (Kim et al., 2003).

Outcome Questionnaire. The OQ-45.2 (a 45-item, 5 point Likert-type scale with $0=$ never to $4=$ almost always) was used to assess male trainees' level of psychological 
distress. The measure was designed to be, in part, as an assessment of baseline psychological functioning across various spheres (i.e., how the person feels inside, how the person is getting along with significant others, and how the person is doing in important life tasks). This measure was also developed to assess common symptoms of adult psychopathology. Lambert et al. (2004) reported the OQ-45.2 to have sound internal consistency $(r=.93)$ and three-week test-retest reliability $(r=.84)$. Concurrent validity was found to be moderate to high ( $r$ values of .50 to .85 ) when correlated with measures most often used to assess psychotherapy outcome in clinical trials (e.g., Beck Depression Inventory, State-Trait Anxiety Inventory). The measure has been validated and used across various settings and populations (e.g., college counseling center, community outpatient clinic, inpatient psychiatric group). The OQ-45.2 has three subscales that measure quality of interpersonal relations, social role functioning, and symptom distress (Lambert et al., 1996). However, these subscales have been shown to be highly correlated, thus suggesting that the OQ-45.2 can be described best by a single factor (Mueller, Lambert, \& Burlingame, 1998).

Demographic questionnaire. The demographic form requested that participants supply basic information about their age, race, ethnicity, religious and sexual orientations. Participants were also asked to provide the location of their doctoral program, their degree sought (Ph.D., or Psy.D.) and their program specialty (i.e., Clinical or Counseling) as well as their years completed in that program, and completed number of multicultural counseling courses. Finally, the questionnaire requested participants to provide information regarding the length of their primary advising relationship, the sex 
and sexual orientation or their primary advisor, and their total number of advisory relationships during training.

\section{Design}

The first goal of this investigation was to demonstrate what, if any mean differences existed between male psychology trainees' scores on the four subscales of the GRCS as compared to established scores from a normative male sample. The second goal of this investigation was to explore the predictability of male trainees' patterns of gender role conflict on psychological distress. The third goal of this study was to explore the predictability of male trainees' patterns of gender role conflict on advisory working alliance. The final goal was to examine the predictability of male trainees' patterns of gender role conflict on multicultural awareness. Also, further power analyses were run to determine whether the exploration of within-group differences (e.g., gay and heterosexual male doctoral students) was permissible vis-à-vis GRC, advisory working alliance, multicultural awareness, and psychological distress. Such analyses were treated as exploratory.

In sum, this study involved the following sets of variables: (a) the gender role conflict set of variables include the four patterns of GRC (i.e., SPC, RE, RABBM, and CBWFR); and, (b) the relevant training environment variables, (i.e., advisory working alliance, multicultural awareness, psychological distress).

Initially, descriptive statistics were presented on all variables. Next, one-sample $t$ tests were used to test for mean GRCS score differences between the current sample of male doctoral psychology trainees and mean scores from a normative male sample. Next, multiple regression analyses were used to evaluate the associations between GRC and (a) 
the advisory working alliance, (b) multicultural awareness, and (c) psychological distress, respectively. Lastly, two exploratory MANOVAs were run to determine whether withingroup differences (e.g., gay and heterosexual male doctoral students) exist vis-à-vis both GRC and advisory working alliance variables.

First, it was predicted that male psychology graduate trainees would report lower mean scores on all four patterns of GRC when compared to a normative male sample. Second, it was predicted that male trainees' patterns of gender role conflict would be predictive of advisory working alliance. In particular, that restrictive emotionality and success, power, competition would be associated with a poorer advisory working alliance. Finally, it was predicted that patterns of gender role conflict would be predictive of psychological distress. Specifically, that restrictive emotionality, conflict between work and family relations and success, power, competition would be associated with psychological distress. Data was analyzed using the Statistical Package for Social Sciences (SPSS).

\section{Procedure}

Participants in the study were asked to complete four measures (i.e., GRCS, AWAI-S, MAKSS-CE-R - Awareness subscale, OQ-45.2), and to provide demographic and programmatic information.

Participant recruitment. Participants were recruited internationally through purposeful sampling. Specifically, from February through March 2010, the training directors of 307 APA accredited Clinical $(n=238)$ and Counseling $(n=69)$ psychology doctoral programs in the United States, Canada and Puerto Rico were contacted through email. The list of accredited programs was compiled by the APA Education Directorate. 
This email, which included the recruitment letter (Appendix G), requested that they forward or otherwise make available the call for participation to qualified male students in their program. Participants who received the email recruitment letter found it to contain an address link to the electronic survey instrument. This website included an informed consent with a description of the study (Appendix F), a demographic questionnaire (Appendix A), and four measures (Appendix B, Appendix C, Appendix D, Appendix E).

Before data collection began, approval for the study was obtained from the university's institutional review board. Also, permission was obtained from each measure's author to place the instrument online. Participants were informed that participation is both voluntary and anonymous, and that they may discontinue participation at any time. They were told that participation will involve answering questions regarding gender roles, their advising relationship, multicultural competency and psychological functioning. Finally, the researcher provided the participants with contact information, should they have any questions or concerns regarding the study. 


\section{CHAPTER IV}

\section{Results}

In this chapter, the results of the study are presented. First, descriptive statistics of the sample will be provided. Then the results of each hypothesis will be presented. Finally, the results of exploratory analyses will be offered.

\section{Description of Sample}

Eighty training directors (26\%) replied to the solicitation email and confirmed that they had made the call for participation available to their male students, $10(3 \%)$ reported that they could not forward the call for participation for various reasons (e.g., program no longer exists, university/program policy), and 3 (I\%) replied that they currently had no male students in their doctoral psychology programs. The participation status of the remainder of training directors $(70 \%, n=214)$ is unknown (i.e., they did not reply directly to the primary investigator's inquiries regarding their assistance with participation). It is also not known how many male students were actually sent the invitation to participate and opted not to complete the measures. Thus, the method by which participants were solicited to participate (i.e., purposeful sampling via email) limits the value of a response rate as it can not be definitively known how many training directors, and by extension male students, received the call for participation. In light of this limitation, the generalizability of this sample to APA demographics will be presented later in this chapter.

A total of 342 male doctoral students participated in the study. After adjusting for incomplete participant responses, a total of 302 complete and usable questionnaires remained. Given the adequate sample size obtained to complete analyses, casewise 
deletion was determined to be the most appropriate method to initially handle missing data. In all 40 deleted cases, data were missing on at least $25 \%$ of the study's measures (i.e., GRCS, AWAI-S, MAKSS - Awareness, OQ-45.2,). In the majority of these deleted cases (i.e., 27), participants ceased to continue during or after completion of the initial measure. In the remainder of these incomplete cases, attrition continued as participants moved throughout the other measures of the survey. Refusal to respond to all measures was not related to participant characteristics (e.g., years of doctoral training, race, advisor status). Thus, this attrition is seen as a lack of interest in the subject or the time demand of participation. For the remaining 302 participants, occasional missing data were managed through single imputation of values. Specifically, as the occurrence of missing data were rare (i.e., <.001\%), mean item values were substituted. Demographic data omissions were not treated with imputation or casewise deletion as these data was treated as optional.

Descriptive statistics. The majority of male doctoral students in this sample were White $(81.5 \%, n=246)$, with $7(2.3 \%)$ identifying as Black, $13(4.3 \%)$ as Latino, $9(3 \%)$ as Asian, $2(0.7 \%)$ as Native American, $10(3.3 \%)$ as Bi-Racial, $4(1.3 \%)$ as Multi-Racial, and $11(3.6 \%)$ who elected not to provide their race. This sample ranged in age from 22 to 53 years; with a mean age of $29.1(M d n=28, S D=4.76)$. With regard to sexual orientation, approximately $78 \%$ of students identified as heterosexual $(n=234), 17 \%$ as gay $(n=52)$ and $5 \%$ as bisexual $(n=15)$. Approximately $67.2 \%(n=203)$ of participants were students in Ph.D. programs, and 32.1\% $(n=97)$ in Psy.D. programs. With regard to specialty, the majority of men in this sample were in Clinical programs $(74.8 \%, n=226)$, with $73(24.2 \%)$ Counseling psychology participants. Participants in this sample ranged 
in their year of doctoral training $(M=3.21, M d n=3, S D=1.72)$, with 56 in their first year, 64 in their second year, 55 in their third year, 58 in their fourth year, 41 in their fifth year, 16 in their sixth year, and 11 between their seventh and tenth year.

Geographical locations of the participants' programs were as follows: 82 (27.2\%) Mid Atlantic, 59 (19.5\%) Great Lakes, 30 (9.9\%) South Central, 25 (8.3\%) South, $22(7.3 \%)$ Pacific West, 17 (5.6\%) Mid-South, 17 (5.6\%) Northwest, 14 (4.6\%) New England, 10 (3.3\%) Southwest, $10(3.3 \%)$ Canada, and $9(3 \%)$ Upper Plains.

In order to better contextualize and inform these results, the representativeness of this sample was compared to the larger population of male APA doctoral students on several relevant demographic dimensions (i.e., race/ethnicity, age, sexual orientation). Thus, data from The APA Commission on Accreditation and APA Office of Program Consultation and Accreditation, Research Committee was requested. These offices provided demographic information from the 2010 Annual Report Online. This report is a composite of programmatic data from a survey 289 APA-accredited Clinical and Counseling doctoral training directors in the U.S., representing 23, 258 students. Five Canadian programs were excluded, as they are not required to track or report ethnicity statistics. Unfortunately, neither age nor sexual orientation statistics were tracked by these APA offices. Of the doctoral students accounted for in this report, approximately $23 \%(n=5,430)$ were male; with roughly $72 \%$ of this male population identifying as Caucasian $(n=3,888), 5 \%(n=282)$ identifying as African American-Black, $9 \%(n=$ $475)$ as Hispanic-Latino, $7 \%(n=353)$ as Asian-Pacific Islander, .7\% $(n=38)$ as American Indian - Alaskan Native, 3\% $(n=160)$ as Multi-Ethnic, 1\% $(n=68)$ as not 
reporting race and $1 \%(n=57)$ who indicated 'other'(American Psychological Association, 2010).

The racial representativeness of this sample to the population of male APA doctoral students was calculated through chi-square analysis (See Table 1). I sought to answer how well the frequencies associated with race in this sample matched the expected racial frequencies found in the national sample. Results of the one-sample chisquare analysis indicate that the racial proportions of this sample are significantly different from those found in the population of male APA doctoral students, $\chi^{2}(5, N=$ $292)=68.3, p<.01$. However, while this finding disconfirms that this sample is the same as the expected racial breakdowns of the larger population, the effect size of .05 indicates that the observed racial frequencies deviate only minutely from the expected frequencies. The proportion of men in this sample who identified as White $(P=.82)$ was greater than the expected proportion of .72. Similarly, the proportion of men who identified as Bi or Multi-Racial $(P=.05)$ was greater than the expected proportion of .01 . Among the men in this sample who identified as Black $(P=.02)$, Latino $(P=.04)$, Asian $(P=.03)$ and Native American $(P=.01)$, greater proportions of their respective races were found in the larger population, with .05 identifying as Black, .09 as Latino, .07 as Asian, and .03 as Native American. Overall, this sample was discrepant against the larger population due to an underrepresentation of Black $(N=-8)$, Latino $(N=-13)$, Asian $(N=-11)$ and Native 
Table 1

Summary of chi-square analysis of racial frequencies in sample

\begin{tabular}{lcccc}
\hline & Observed $N$ & Expected $N$ & Residual $N$ & $d$ \\
\hline White & & & & $\chi^{2}$ \\
Black & 246 & 209 & 37 & -8 \\
Latino & 7 & 15 & -13 \\
Asian & 13 & 26 & -11 \\
Native American & 9 & 20 & -7 & 11 \\
Multi-Racial & 2 & 9 & & .05 \\
Total & 14 & & & 68.33 \\
Chi-square & 291 & & & \\
.000 & & & & \\
\end{tabular}


American $(N=-7)$ men and a slight overrepresentation of men identifying as White $(N=$ 37) and Bi or Multi-Racial $(N=11)$.

With regard to demographics relevant to doctoral training, students in this sample reported having had completed approximately two multicultural counseling courses to date $(M=2.39, M d n=2, S D=1.36)$. In terms of advisory relationships, 158 participants $(52 \%)$ reported having had one advising relationship in their training to date $(M=2.69$, $M d n=2, S D=.97)-$ with $104(34 \%)$ having had two such relationships, and $38(13 \%)$ having had between three and five advising relationships. Participants reported that their most current advisory relationship has lasted for more than two years $(M=2.72, M d n=$ $2.5, S D=1.79)$. Approximately $55 \%(n=166)$ of participants' advisors were male and $44.4 \%$ were female. The majority of participants' advisors in this sample were believed by the participants to be heterosexual $(84.8 \%, n=256)$, with $23(7.6 \%)$ identifying their advisors as gay, lesbian, or bisexual. Twenty-two (7.3\%) participants left their advisors' perceived sexual orientation as unidentified. It is important to note that the statistics reported above reflect only participants who supplied demographic information. Thus, due to small amounts of missing and/or excluded data, percentages and frequencies in these demographic categories did not always total $100 \%(n=302)$.

\section{Male Psychology Doctoral Students and GRC Norms}

The first aim of this study was to establish how this sample compared to a normative male sample on the four patterns of GRC. It was hypothesized that male psychology doctoral students would report lower overall scores on the GRCS and its four subscales (i.e., SPC, RE, RABBM and CBWFR). Prior to comparing these mean scores via one sample $t$-test, a normative male sample was developed. 
Normative male GRC sample. To best create the representative GRCS score norms of this theoretical population (i.e., men), aggregate data from The Gender Role Conflict Research Program (O’Neil, n.d.) was referenced and used. This resource provides composite information on hundreds of prior GRC research. This composite data (see Figure 1 for an example), in part, helped to determine which studies/samples were selected - so as to best approximate and represent a comparison group for the sample of men recruited to participate in this study. In total 24 GRC studies/samples were utilized. Before these studies/samples were chosen, relevant findings regarding GRCS differences according to dimensions of identity (secondary to gender) were considered, along with whether any within-group differences existed in this sample on GRCS scores.

First, a preliminary MANOVA was run in order to ascertain whether men in this sample differed significantly on GRCS scores due to race or sexual orientation. With regards to race, results show that the omnibus MANOVA and subsequent follow-up ANOVAs were not significant Wilks' $\Lambda=.99, F(4,286)=.60, p=.66$. Thus, no statistically significant differences were found between participants of Color in this sample and their White counterparts on GRCS scores. There was, however, an effect of sexual orientation on GRC. Overall the omnibus MANOVA was statistically significant Wilks' $\Lambda=.93, F(4,296)=.5 .78, p<.01$. Specifically, subsequent follow-up ANOVAs revealed students in this sample who identified as heterosexual to have score significantly higher on RABBM than students who identified as gay or bisexual $F(1,299)=13.26, p<$ .01. No other GRCS scores statistically differentiated students who identified as heterosexual from those who did not. Next, findings from relevant research was considered. Past empirical studies have begun to demonstrate differences in GRC due to 
TABLE 12 - SUMMARY OF NORMATIVE DATA ALL POPULATION'S GRC

Raw GRCS Scores Average Means Across Numerous Studies

NUMBER OF STUDIES

TOTAL

\begin{tabular}{|c|c|c|c|c|c|}
\hline $\begin{array}{l}\text { POPULATIONS } \\
\text { SCORE }\end{array}$ & SPC & RE & RABBM & CBWF & \\
\hline $\begin{array}{l}\text { White College } \\
\text { Students } \\
\mathrm{N}=8\end{array}$ & 53.80 & 32.12 & 30.82 & 22.55 & 139.53 \\
\hline $\begin{array}{l}\text { Adult White Men } \\
\mathrm{N}=8\end{array}$ & 44.49 & 30.77 & 26.40 & 22.23 & 124.99 \\
\hline $\begin{array}{l}\text { African American } \\
\text { Men } \\
\mathrm{N}=5\end{array}$ & 45.78 & 36.38 & 29.08 & 21.64 & 127.74 \\
\hline $\begin{array}{l}\text { Asian American } \\
\text { Men } \\
N=3\end{array}$ & 50.70 & 31.95 & 26.77 & 22.62 & 133.05 \\
\hline $\begin{array}{l}\text { Hispanic/Latino } \\
\text { Men } \\
\mathrm{N}=2\end{array}$ & 51.09 & 32.50 & 29.40 & 22.10 & 135.60 \\
\hline $\begin{array}{l}\text { Gay Men } \\
\mathrm{N}=4\end{array}$ & 44.50 & 28.80 & 19.08 & 20.09 & 113.49 \\
\hline $\begin{array}{l}\text { Older Retired } \\
\text { Men } \\
\mathrm{N}=2\end{array}$ & 45.70 & 33.56 & 27.20 & 18.92 & 125.38 \\
\hline $\begin{array}{l}\text { College Women } \\
\mathrm{N}=4\end{array}$ & 46.82 & 28.16 & 20.76 & 23.62 & 119.39 \\
\hline
\end{tabular}

1

SPC $=$ Success Power Competition

$\mathrm{RE}=$ Restrictive Emotionality

$\mathrm{RABBM}=$ Restrictive Affectionate Behavior Between Men

CBWFR = Conflict Between Work and Family Relations

Figure 1. Normative GRC data example from The Gender Role Conflict Research

Program 
dimensions of diversity (see O'Neil 2008 for a complete review). Although this line of research is limited, results indicate how both sexual orientation and age affect GRC scores. Specifically, findings have shown gay males to have lower scores on certain GRCS subscales (i.e., RE, RABBM) than their heterosexual counterparts. With regards to age, studies have found that younger men produce higher scores on SPC and RABBM than older men.

These findings, along with the results of the aforementioned MANOVA, and the composite data provided by The Gender Role Conflict Research Program (O’Neil, n.d.), were used to inform which studies, and coinciding mean GRCS scores, were included to create the aggregate GRCS scores of the representative normative sample in this study. To further specify, the mean GRCS scores from the mean GRCS scores from select, past studies (i.e., 24) were combined and averaged (see Table 2). The numerical composition of these studies' samples according to race is as follows: African American Men $(n=5)$, predominantly White Adult Men $(n=8)$, Asian American Men $(n=3)$, predominantly White College Students $(n=8)$, and Hispanic/Latino Men $(n=2)$. On the other hand, the aggregate mean GRC subscale scores from studies of exclusively gay men and older retired men were not included - as these groups have been empirically shown to produce different patterns of GRC and were also not deemed most representative of the gendered experience of male doctoral psychology trainees. Through this process, a normative sample of men was created with established test values for each of the four GRC subscales and total GRC score.

One sample t-tests. Results indicate that men in this sample produced significantly lower GRCS scores than mean population scores on Restrictive 
Table 2

GRC Studies of Diverse Men Used to Create Normative Male Comparison Sample

\begin{tabular}{|c|c|c|c|c|c|c|c|c|}
\hline \multirow{2}{*}{$\begin{array}{l}\text { Populations } \\
\text { Citations }\end{array}$} & \multirow[t]{2}{*}{$\mathrm{N}$} & \multicolumn{4}{|c|}{ GRCS $M$ Scores $(S D)$} & \multicolumn{3}{|c|}{ Mean Age \& Race } \\
\hline & & Total Score & $\mathrm{SPC}$ & $\mathrm{RE}$ & RABBM & CBWFR & & \\
\hline White College Students & 8 & 139.53 & 53.80 & 32.12 & 30.82 & 22.55 & & \\
\hline O'Neil et al. (1986) & 527 & 133.94 & 53.18 & 30.27 & 29.09 & 21.4 & 19.8 & \\
\hline Good \& Wood (1995) & 397 & 147.10 & $55.60(10.5)$ & $33.60(9.8)$ & $34.20(8.7)$ & $23.70(6.1)$ & 19.3 & $82 \% \mathrm{~W}$ \\
\hline \multirow[t]{3}{*}{ Good et al. (1995) } & 107 & $139.84(22.43)$ & $53.15(9.87)$ & $31.42(8.66)$ & $31.93(8.64)$ & $23.35(5.8)$ & & $89 \% \mathrm{~W}$ \\
\hline & 535 & $145.43(22.76)$ & $56.38(9.12)$ & $33.23(8.35)$ & $30.84(7.61)$ & $22.98(5.58)$ & 19 & $91 \% \mathrm{~W}$ \\
\hline & 401 & $147.05(24.30)$ & $55.58(10.43)$ & $33.58(10.43)$ & $34.23(8.72)$ & $23.66(6.12)$ & 19 & $82 \% \overline{\mathrm{W}}$ \\
\hline Wade \& Gelso (1998) & 240 & $140.45(24.04)$ & $54.17(11.30)$ & $33.24(8.71)$ & $30.09(7.81)$ & $22.95(5.62)$ & 19.23 & $66 \% \mathrm{~W}$ \\
\hline Cournoyer \& Mahalik (1995) & 88 & 131.12 & $50.02(12.99)$ & $31.29(9.93)$ & $28.62(9.07)$ & $21.01(7.39)$ & 19.81 & $88 \% \mathrm{~W}$ \\
\hline Rochlen \& O'Brien (2002) & 301 & $131.77(25.26)$ & $52.55(10.82)$ & $30.27(9.43)$ & $27.57(8.57)$ & $21.37(6.45)$ & 19.65 & $64 \% \mathrm{~W}$ \\
\hline Adult White Men & 8 & 124.99 & 44.49 & 30.77 & 26.40 & 22.23 & & \\
\hline Campbell \& Snow (1992) & 70 & 133.94 & 45.20 & 30.70 & 27.50 & 22.30 & 40.1 & $79 \% \mathrm{~W}$ \\
\hline Cournoyer \& Mahalik (1995) & 89 & 127.84 & $44.87(10.48)$ & $32.61(9.89)$ & $27.25(8.25)$ & $23.12(6.53)$ & 40.96 & $99 \% \mathrm{~W}$ \\
\hline Sileo (1996) & 150 & $128.02(31.14)$ & $47.33(11.35)$ & $30.75(12.01)$ & $26.62(10.62)$ & $23.33(6.89)$ & 36.41 & $100 \% \mathrm{~W}$ \\
\hline Alexander (1999) & 179 & 127.82 & $43.00(10.86)$ & $34.17(9.92)$ & $26.47(8.41)$ & $24.18(6.17)$ & 36.4 & $91 \% \mathrm{~W}$ \\
\hline Sharpe et al. (1995) & 88 & 126.19 & $45.75(10.51)$ & $31.43(10.21)$ & $28.68(9.35)$ & $20.33(7.37)$ & 50 & $94 \% \mathrm{~W}$ \\
\hline Cortese (2003) & 308 & $118.21(27.46)$ & $44.19(11.18)$ & $28.17(9.98)$ & $23.55(9.01)$ & $22.00(7.00)$ & 44.32 & $63 \% \mathrm{~W}$ \\
\hline Swenson (1998) & 85 & 108.71 & $38.84(10.39)$ & $27.96(10.08)$ & $21.89(9.08)$ & $20.02(6.83)$ & 38.4 & $82 \% \mathrm{~W}$ \\
\hline Chamberlin (1993) & 188 & $129.26(24.2)$ & $46.8(10.44)$ & $30.40(10.53)$ & $29.30(8.09)$ & $22.60(6.57)$ & 46 & \\
\hline
\end{tabular}


subscale; RABBM = Restrictive Affectionate Behavior Between Men subscale; CBWFR = Conflicts Between Work and

Family Relations subscale; $\mathrm{W}=$ White. Standard deviations not included were either not provided by researcher(s) or reported for item range, rather than raw scale scores. 
Table 2 (continued)

GRCS Studies of Diverse Men Used to Create Normative Male Comparison Sample

\begin{tabular}{|c|c|c|c|c|c|c|c|}
\hline \multirow{2}{*}{$\begin{array}{l}\text { Population } \\
\text { Citations }\end{array}$} & \multirow[t]{2}{*}{$\mathrm{N}$} & \multicolumn{4}{|c|}{ GRCS $M$ Scores $(S D)$} & \multirow[b]{2}{*}{ CBWFR } & \multirow[t]{2}{*}{ Mean Age } \\
\hline & & Total Score & SPC & $\mathrm{RE}$ & RABBM & & \\
\hline African American Men & 5 & 127.74 & 45.78 & 36.38 & 29.08 & 21.64 & \\
\hline Brewer (1998) & 104 & $128.09(35.22)$ & $47.02(12.45)$ & $32.80(11.69)$ & $26.77(10.02)$ & $21.51(7.13)$ & 39.5 \\
\hline Laurent (1997) & 193 & 134.21 & $47.58(14.03)$ & $34.87(11.03)$ & $28.78(11.35)$ & $22.98(7.04)$ & 28.6 \\
\hline Wade (1996) & 95 & 121.30 & 46.93 & 29.20 & 25.44 & 20.34 & 43.5 \\
\hline White (2002) & 271 & 125.80 & 37.70 & 39.50 & 27.68 & 20.70 & College Men \\
\hline Lily (1999) & 80 & $129.33(24.91)$ & $49.67(12.74)$ & $45.54(11.45)$ & $36.75(9.59)$ & $22.69(8.02)$ & 24.96 \\
\hline Asian American Men & 4 & 133.05 & 51.07 & 31.95 & 26.77 & 22.62 & \\
\hline Kim et al. (1996) & 125 & 134.31 & 51.87 & 31.30 & 28.40 & 22.74 & 22 \\
\hline Liu (2002) & 323 & 130.30 & $49.96(10.61)$ & $31.99(8.36)$ & $26.80(7.62)$ & $21.55(5.93)$ & 21.07 \\
\hline Liu \& Iwamoto (2006) & 192 & 134.56 & $53.28(6.70)$ & $32.56(5.80)$ & $25.13(4.70)$ & $23.59(3.42)$ & 23.71 \\
\hline Hispanic/Latino Men & 2 & 135.60 & 51.09 & 32.50 & 29.40 & 22.10 & \\
\hline Leka (1998) & 164 & 137.17 & 52.13 & 31.25 & 30.14 & 22.36 & 21.45 \\
\hline Fragoso \& Kasubeck (2000) & 113 & 134.31 & 50.18 & 34.00 & 28.80 & 21.90 & 38.4 \\
\hline
\end{tabular}

Note. GRCS = Gender Role Conflict Scale; SPC = Success, Power, Competition subscale; RE = Restrictive Emotionality subscale; RABBM = Restrictive Affectionate Behavior Between Men subscale; CBWFR = Conflicts Between Work and Family Relations subscale. Standard deviations and means not included were either not provided by researcher(s) or reported for item range, rather than raw scale scores. 
Emotionality $(\mathrm{RE}), M=24.23, S D=8.05, t(301)=-18.39, p<.001$; Success, Power, Competition (SPC), $M=47.85, S D=10.27, t(301)=-2.58, p=.01$; Restrictive Affectionate Behavior Between Men (RABBM), $M=19.28, S D=6.78, t(301)=-23.6, p$ $<.001)$; and total GRCS score, $M=116.43, S D=21.94, t(301)=-12.48, p<.001$. This sample also produced significantly higher Conflict Between Work and Family Relations (CBWFR) scores than the normative average, $M=25.07, S D=6.26, t(301)=7.89, p$ $<.001$. Therefore, these null hypotheses were rejected as significant differences were found. Men in this sample reported lower overall scores on RE, SPC, and RABBM. Yet, opposite the hypothesized direction, male doctoral students reported greater scores on CBWFR than other men.

\section{The Influence of GRC on Training Variables}

The second aim of this study was to determine how well the GRCS could predict (a) advisory working alliance (AWAI-S), (b) multicultural awareness (MAKSS Awareness) and (c) psychological distress (OQ-45.2). Three multiple regressions were conducted; each using the GRCS subscales as predictors and either AWAI-S, MAKSS awareness or OQ-45.2 as criterion variables. It was hypothesized that, among this sample of doctoral students, specific GRCS subscale scores (i.e., RE, SPC, CBWFR) will predict psychological distress (OQ-45.2). It was further hypothesized that specific GRCS subscale scores (i.e., RE, SPC) will predict advisory working alliance (AWAI-S). No hypothesis was made regarding the predictability of GRCS subscale scores on multicultural awareness (MAKSS - Awareness).

Multiple regression analyses. Results from the three multiple regression analyses indicate that certain GRCS subscale scores statistically predicted both OQ-45.2 
and MAKSS - Awareness. No predictability was found between any GRCS subscale score and AWAI-S.

In the first regression model (i.e., GRC on OQ-45.2), the linear combination of GRC measures was statistically related to the measure of psychological distress, $F(4,97)$ $=23.21, p>.001$. The sample multiple correlation coefficient was .49 , showing that roughly $24 \%$ of the variance of psychological distress was accounted for by the linear combination of GRC measures. All the bivariate correlations between the GRC measures and psychological distress were positive, with two statistically significant GRCS subscale predictors $(p<.001)$. Namely, higher levels of psychological distress scores were significantly associated with higher scores on both Restrictive Emotionality and Conflict Between Work and Family Relations subscales. Supporting this conclusion is the strength of the relationship between the RE measure and psychological distress, which was $.32, p$ $<.001$, as well as the comparable correlation partialling out the effects of the other GRC measures, which was $.24, p<.001$. Similarly, the strength of the relationship between the CBWFR measure and psychological distress, was $.40, p<.001$, with a partial correlation of $.34, p<.001$.

An alarming finding related to levels psychological distress was that men in this sample produced scores on the OQ-45.2 that are well above the cutoff scores differentiating patient from non-patient samples. Based on analyzing the normative data for this measure Lambert et al. (2004) indicates that a total score which falls at or below 63 represents a higher likelihood that the individual be part of community samples as opposed to patient samples. Men in this sample produced a mean score of 91.81 (SD $18.70)$ as compared to scores produced by undergraduate men $(M=42.73, S D=15.89)$, 
men in a community sample $(M=49.2, S D=17.59)$, men treated in a university outpatient clinic $(M=76.27, S D=26.53)$, and men involved in an employee assistance $\operatorname{program}(M=73.52, S D=21.87)$

In the next regression model (i.e., GRC on MAKSS - Awareness), the linear combination of GRC measures was statistically related to the measure of multicultural awareness, $F(4,97)=3.52, p<.01$. The sample multiple correlation coefficient was .21 , showing that approximately $5 \%$ of the variance of multicultural awareness was accounted for by the linear combination of GRC measures. Of the four bivariate correlations between GRC measures and multicultural awareness, two were found to be positive and two negative - with two statistically significant GRCS subscale predictors $(p<.05)$.

Higher multicultural awareness scores were significantly associated with lower scores on both Success, Power, Competition and Restrictive Affectionate Behavior Between Men subscales and vice versa. This interpretation is supported by the strength of the relationship between the SPC measure and the multicultural awareness scale, which was $.17, p<.01$, as well as the comparable correlation partialling out the effects of the other GRC measures, which was also $.17, p<.01$. Similarly, the strength of the relationship between the RABBM measure and multicultural awareness, was $-.1, p<.05$, with a partial correlation of $-.12, p<.05$.

In the final regression model (i.e., GRC on AWAI-S), the omnibus regression comparing regression variance to residual variance was not significant. Furthermore, after inspection, none of the individual predictors were revealed to be significant in this model. Therefore, contrary to hypothesis, no associations were found between measures of GRC and AWAI-S. 
To summarize, the hypothesis that patterns of GRC would predict psychological distress among this population of men was accepted. However, of the three patterns of GRC hypothesized to be significant predictors in this analysis, only RE and CBWFR were statistically significant. The next hypothesis, namely that patterns of GRC would predict advisory working alliance, was rejected. This analysis showed none of the patterns of GRC to be significant predictors - with no predictability of advisory working alliance over chance. As no hypothesis was proposed regarding the predictability of GRC on multicultural awareness, the analysis was exploratory. Yet, results show patterns of GRC to predict multicultural awareness in this sample - with SPC and RABBM as significant predictors.

\section{Exploratory Analyses}

The final aim of this study was to explore within-group differences in relation to both patterns of gender role conflict and the advisory working alliance. Two separate MANOVAs were run to exploring potential differences between participants' GRC and AWAI-S scores based on certain demographic (e.g., race, sexual orientation) and programmatic (e.g., specialty of doctoral program, gender of advisor) identifications. Mean scores on all measures by cultural demography (e.g., race, sexual orientation) can be found in Table 3. 
Table 3

Means of the GRCS, AWAI-S, OQ-45.2 and MAKSS-Awareness by Cultural Demography

\begin{tabular}{lcccccccc}
\hline $\begin{array}{l}\text { Race }(N) \\
\text { Orientation }(N)\end{array}$ & GRCS Total Score & SPC & RE & RABBM & CBWFR & AWAI-S & OQ-45.2 & MAKSS-Awareness \\
\hline White (246) & 115.98 & 47.85 & 24.00 & 19.12 & 25.01 & 85.17 & 91.35 & 25.98 \\
Black (7) & 117.57 & 43.86 & 28.43 & 23.00 & 22.29 & 82.14 & 97.70 & 28.14 \\
Latino (13) & 127.15 & 50.23 & 28.46 & 21.15 & 27.31 & 86.15 & 101.31 & 27.08 \\
Asian (9) & 120.33 & 50.33 & 24.89 & 20.11 & 25.00 & 82.60 & 91.44 & 26.89 \\
Native American (2) & 126.50 & 50.50 & 26.00 & 17.50 & 32.50 & 93.00 & 93.50 & 24.00 \\
Multi-Racial (14) & 112.21 & 46.29 & 23.07 & 18.50 & 24.36 & 84.57 & 90.29 & 26.29 \\
& & & & & & & & \\
Heterosexual (234) & 116.69 & 47.21 & 24.52 & 20.01 & 24.95 & 85.41 & 90.47 & 26.05 \\
Gay (52) & 114.27 & 49.52 & 23.10 & 16.42 & 25.23 & 83.25 & 97.75 & 26.54 \\
Bisexual (15) & 117.86 & 51.13 & 23.60 & 17.47 & 25.67 & 85.20 & 92.53 & 26.27
\end{tabular}

Note. GRCS = Gender Role Conflict Scale; SPC = Success, Power, and Competition subscale; RE = Restrictive Emotionality subscale; RABBM = Restrictive Affectionate Behavior Between Men subscale; CBWFR = Conflicts Between Work and Family Relations subscale; AWAI-S = Advisory Working Alliance Index- Student Version; OQ-45.2 = Outcome

Questionnaire; MAKSS-Awareness = MAKKS = Multicultural Awareness, Knowledge, and Skills Survey- Counselor EditionRevised. 
Exploration of within-group differences on GRC. As mentioned earlier, no statistically significant differences were found between participants of Color in this sample and their White counterparts on GRCS scores, Wilks' $\Lambda=.99, F(4,286)=.60, p$ $=.66$. With regard to sexual orientation, statistical significance was found, Wilks' $\Lambda=$ $.93, F(4,296)=5.78, p<.01$, to differentiate the sample - and subsequently revealed heterosexual participants to have significantly higher RABBM scores $(M=20.01, S D=$ 6.94) than those who identified as gay or bisexual, $F(1,299)=13.26, p<.01, M=16.66$, $S D=5.49$. In addition, MANOVA results show that both the perceived sexual orientation of participants' advisors, Wilks' $\Lambda=.93, F(4,293)=1.29, p=.20$, and the sex of participants' advisors, Wilks' $\Lambda=.99, F(4,295)=.50, p=.74$, failed to differentiate GRCS scores within the sample. Similarly, no statistically significant differences were found between type of degree awarded, Wilks' $\Lambda=.99, F(4,295)=.76, p=.55$ and program specialty, Wilks' $\Lambda=.92, F(4,294)=.57, p=.68$ on GRCS scores.

\section{Exploration of within-group differences on AWAI-S. An exploratory}

MANOVA was conducted on the AWAI-S and its subscales (i.e., Rapport, Apprenticeship and Identification-Individuation) and within-group differences - namely sex of advisor, sexual orientation of advisor, and participant sexual orientation. Results of this analysis show no statistically significant differences between participants who identified having a male advisor from those who identified having a female advisor on AWAI-S scores, Wilks' $\Lambda=.99, F(3,296)=.59, p=.63$. Furthermore, the perceived sexual orientation of participants' advisors, Wilks' $\Lambda=.95, F(3,294)=1.29, p=.31$ did not differentiate AWAI-S scores. With regard to participants' sexual orientation, statistical significance was found, Wilks' $\Lambda=.97, F(3,297)=3.35, p<.05$. Specifically, 
heterosexual participants reported significantly higher Rapport $(M=26.79, S D=4.36)$ and Identification-Individuation $(M=13.33, S D=4.05)$ scores than did those who identified to other orientations on Rapport, $F(1,299)=10.06, p<.01 ; M=25, S D=3$; and Identification-Individuation, $F(1,299)=4.6, p<.05 ; M=12.16, S D=3.44$.

\section{Conclusion}

In sum, participants in this sample of male psychology doctoral students were found to score differently than a normative male sample on measures of gender role conflict. Findings also show that participants' psychological distress was predicted by certain patterns of gender role conflict. So too, were their multicultural awareness predicated by patterns of gender role conflict. Results failed to indicate that participants' advisory working alliance scores could be predicted by patterns of gender role conflict. Furthermore, exploratory analyses of within-group differences on both gender role conflict and advisory working alliance revealed some statistically significant findings. First, men in this sample who did not identify as heterosexual had lower scores on the RABBM pattern of gender role conflict. Lastly, men in this sample who identified as heterosexual had greater scores on the Rapport and Identification-Individuation aspects of advisory working alliance. Next, the findings of this study will be discussed in conjunction with existing scholarship and methodological limitations. 


\section{CHAPTER V}

\section{Discussion}

In this chapter, results will be interpreted in light of the research questions and individual hypotheses. These results will be discussed alongside relevant literature and divided into three sections: (a) GRC Among Male Psychology Doctoral Students, (b) GRC and Aspects of Psychology Training, (c) Exploration of Within-Group Differences. Next, limitations of the study will be presented. Finally, recommendations for further research will be offered.

\section{Interpretation of Findings}

This study investigated the gendered experience of male psychology doctoral students with the aim of extending the knowledge regarding GRC and three dimensions of psychology training (i.e., the advisory relationship, multicultural awareness and psychological distress). The first purpose was to describe and compare the experienced patterns of GRC among these trainees against a larger sample of men. The second purpose was to establish the associations between patterns of GRC and the abovementioned aspects of psychology training. The final purpose of this study was to provide a description of this sample of men that is inclusive of additional dimensions of identity (e.g., race, sexual orientation). In line with this purpose, an exploratory examination was made into how within-group differences manifested in relation to both patterns of gender role conflict and the advisory working alliance.

GRC among male psychology doctoral students. The initial question that guided this research was how do male psychology doctoral students' experiences of gender role conflict compare to those of an empirically established normative male 
sample? It was hypothesized that when compared to a larger sample of men, these men would achieve lower overall scores on each of the four subscales of the Gender Role Conflict Scale. Results largely confirmed this hypothesis, with male psychology doctoral trainees producing lower levels of Success, Power, Competition, Restrictive Emotionality, Restrictive Affectionate Behavior Between Men as well as total degree of gender role conflict. Contrary to prediction, however, these men produced higher levels of Conflict Between Work and Family Relations (see Table 4 for means of all variables).

As no prior research has measured the gender role conflict of male doctoral students as compared to other men, supposition regarding their relative experience of gender role conflict was based on findings and positions taken from prior scholarship in the area of men and masculinity. Perhaps the most relevant finding (Wisch \& Mahalik, 1999), indicated differences between experienced male therapists (mostly doctoral level and practicing an average of 22.04 years) and other samples of men on two of four patterns of gender role conflict. Yet, given certain differences between the men in the 1999 study and mine (e.g., age, clinical setting, years of experience) I sought additional scholarly thought and evidence to better inform my hypothesis.

One line of thought suggests that men who pursue doctoral-level training in psychology may have lesser overall conflict with socialized gender roles by virtue of their pursuit of a non-traditionally male profession that values help seeking - despite this deviation from tradition male norms (e.g., Dodson \& Borders, 2006; Tokar \& Jome, 1998). Although no literature could be found to suggest what gender ascription is made to the profession of psychologist, studies show that the field does not have a noticeably 


\section{Table 4}

Means, Standard Deviations and Ranges of the GRCS, AWAI-S, OQ-45.2 and MAKSS-Awareness

\begin{tabular}{lrrrr}
\hline Variable & M & SD & Observed Range & Possible Range \\
\hline Gender Role Conflict Scale (GRCS) & 116.43 & 21.94 & $58-176$ & $37-222$ \\
Success, Power, Competition (SPC) & 47.85 & 10.27 & $22-76$ & $13-78$ \\
Restrictive Emotionality (RE) & 24.23 & 8.05 & $10-50$ & $10-60$ \\
Restrictive Affectionate Behavior Between Men (RABBM) & 19.28 & 6.78 & $8-43$ & $8-64$ \\
Conflict Between Work and Family Relations (CBWFR) & 25.07 & 6.26 & $8-36$ & $6-36$ \\
Advisory Working Alliance Inventory, Student Version (AWAI-S) & 84.99 & 7.43 & $62-105$ & $30-150$ \\
Rapport & 26.39 & 4.15 & $20-42$ & $11-55$ \\
Identification-Individuation & 13.10 & 3.96 & $5-24$ & $5-25$ \\
Apprenticeship & 45.51 & 7.40 & $24-59$ & $14-70$ \\
Outcome Questionnaire (OQ-45.2) & 91.81 & 18.70 & $54-159$ & $0-225$ \\
Multicultural Awareness, Knowledge, and Skills Survey & 26.16 & 3.42 & $17-35$ & $4-40$ \\
(MAKSS-CE-R) - Awareness Subscale & & & &
\end{tabular}


male numerical majority (Hart, 2009; Munley, Pate, \& Duncan, 2008) nor a traditionally male task orientation. Psychotherapy, for example, runs particularly contrary to traditional masculine ideologies due to its emphasis on personal problems, a more traditionally female affective style of expression, and the reliance on another for assistance (Kiselica, 2001; Wester et al., 2002).

Based on these data and larger line of reasoning, it was assumed that men who had committed to doctoral programs in psychology were attracted to the profession due to a perceived congruence between aspects of their personal identity (e.g., gender) and the professional tasks and demands, as well as their projected ability to manage those tasks and demands. Taken together, these arguments and findings, which informed my initial hypothesis, were largely corroborated by the results of this study - that male psychology trainees experience less overall gender role conflict than a larger population of men.

However, the finding that males in this sample reported significantly higher patterns of Conflict Between Work and Family Relations conflicted with my hypothesis. This pattern of gender role conflict "reflects experiencing restrictions in balancing work, school, and family relations resulting in health problems, overwork, stress, and a lack of leisure and relaxation" (O’Neil, 2008, p. 367). This result is more consistent with a prior finding that experienced male therapists did not significantly differ from other male samples on this pattern (Wisch \& Mahalik, 1999). These researchers attributed similarity on this pattern of conflict to the career and relational tensions of male therapists, and other men alike. Yet, the results of the present study suggest that men in psychology training programs are experiencing greater clash regarding professional and relational activities than do other men. While the logic that "therapists are highly career and family 
oriented" (Wisch and Mahalik, p.57) likely begins to explain this current finding, it can further be conjectured that the unique and often-times competing demands of doctoral training (e.g., satisfying course requirements, developing clinical skills, producing research, becoming involved in the professional community) makes the simultaneous management of career and relational spheres especially taxing. Over and above the rigors of training, perhaps this increased degree of conflict between work and family spheres is related to the intrapersonal standards and expectations which these men hold themselves to. That is, perhaps these men have a greater desire to be emotionally available and involved with family and are subsequently more acutely aware and bothered by tensions that arise.

It is also possible that this especially high form of gender role conflict can be also attributed to the temporal demand of training programs being at odds with male developmental factors. Conceivably, male trainees experience greater than average tension between relational and career demands by virtue of the fact that the time committed to doctoral programs inherently complicates, or delays, the achievement of more traditional masculine developmental markers (e.g., career advancement, financial stability, romantic commitment and family planning). As compared to peers of their age group, male trainees may be less likely to experience agency in other spheres of life perhaps due to the limited power inherent in being a student. Thus, in addition to difficulties balancing social and training demands, this perceived developmental lag may be further psychologically distressing.

GRC and aspects of psychology training. In this study, I also questioned how the gender role conflict of male psychology doctoral students influences dimensions of 
their training experience. That is, how well do specific patterns gender role conflict predict or associate with (a) degree of experienced psychological distress, (b) quality of advisory working alliance, and (c) level of multicultural awareness.

GRC and psychological distress. It was hypothesized that specific patterns of gender role conflict, namely Restrictive Emotionality, Success, Power, Competition, and Conflict Between Work and Family Relations, would predict psychological distress among this sample of doctoral students. Results confirmed the majority of this hypothesis, with trainees' level of psychological distress being associated with levels of gender role conflict. This result was not particularly surprising; as many expressions of gender role conflict have been empirically related to aspects of psychological distress (see O'Neil, 2008 for a complete review) similar to those assessed by the OQ-45.2 measure - namely, interpersonal relations, social role functioning, and symptom distress). Indeed surprising was the mean total score obtained by men in this sample (i.e., 91.81 , SD 18.70) on the OQ-45.2 as compared to the established cutoff score of 63 (Lambert et al., 2004). A high score (i.e., a total score above 63) indicates an individual's admission to "a large number of symptoms of distress (mainly anxiety, depression, somatic problems and stress), as well as interpersonal difficulties, difficulties in social roles (e.g., work problems) and in their quality of life" (Lambert et al., p. 19-20). Hence, on this screening measure, male psychology trainees endorsed significantly high and clinical level of psychological distress. In light of other results from this study, namely lower amounts of restrictive emotionality among these men, an interpretation could be made that their high scores on this measure of distress are related to a greater willingness and openness to endorse aspects of personal difficulty. However, until further empirical 
attention is given to the experiences of male trainees, it would be imprudent to be satisfied with this potential interpretation, and overlook data which clearly indicates these men to be showing signs of clinical distress.

Findings indicate both restrictive emotionality and conflict between work and family relations to be significant in predicting psychological distress (see Table 5). This suggests that trainees who have specific masculine restrictions around their externalization of affect, self-care, and balancing social demands are especially likely to report experiencing various psychological symptoms. Furthermore, men in this sample have expressed a degree of psychological distress similar to, if not greater than, that found in clinical normative samples of men. The implications of these findings are apparent; given the deleterious effects which the development of clinical symptoms (or even sub-clinical distress) can have on the functioning and competency of a trainee. Although specific gender differences in impairment during training have yet to be established by researchers (e.g., Forrest et al., 1999), it would behoove both men in doctoral programs and those involved in their training to become aware of the potential manifestations of these particular masculine conflicts and associated symptoms of distress. In this way, the progression of these gender role conflicts toward more developed symptoms can be addressed and possibly prevented. However, given the results of this study, it is likely that some male trainees are currently experiencing significant levels of distress that may already be impairing their functioning.

Interestingly, against my hypothesis, levels of success, power, competition were not especially influential with regards to psychological distress. First and foremost, this finding may be simply explained by the aforementioned lower average experience of 
Table 5

Summary of Multiple Linear Regression Analysis of GRCS Variables Predicting OQ-45.2

\begin{tabular}{|c|c|c|c|c|c|c|c|c|}
\hline \multirow[t]{2}{*}{ GRC Variables } & \multicolumn{4}{|c|}{ F Test } & \multicolumn{2}{|c|}{ Beta Weight } & \multicolumn{2}{|c|}{ Correlations } \\
\hline & $R$ & $R^{2}$ & $F$ & $p$ & $\beta$ & $p$ & Zero-order & Partial \\
\hline$\overline{\text { GRC Model }}$ & .48 & .24 & 23.21 & .000 & & & & \\
\hline SPC & & & & & .06 & .27 & .26 & .06 \\
\hline $\mathrm{RE}$ & & & & & .29 & .000 & $.32 * * *$ & $.24 * * *$ \\
\hline RABBM & & & & & -.04 & .60 & .24 & -.03 \\
\hline CBWFR & & & & & .35 & .000 & $.40 * * *$ & $.34 * * *$ \\
\hline
\end{tabular}

Note . GRCS = Gender Role Conflict Scale; SPC = Success, Power, Competition subscale; RE = Restrictive Emotionality subscale; RABBM = Restrictive Affectionate Behavior Between Men subscale; CBWFR = Conflicts Between Work and Family Relations subscale. OQ-45.2 = Outcome Questionnaire, version 45.2.*p<.05; *** $p<.01 ; * * * p<.001$. 
male trainees on this pattern of conflict. Although driven, at least in part, by an achievement orientation (i.e., the pursuit of a terminal graduate degree), the means to this end does not appear to include an over-reliance on power and/or control. Thus, less focus on these traditionally male attitudes leads to less conflict around them, and by extension, less psychological distress. A second interpretation hinges on the notion that the doctoral training environment does not strongly activate the stereotyped male tendency to orient towards an attitude of power and control. Therefore, male trainees do not feel compelled to limit their pursuit of programmatic success to behaviors, which involve dominance, influence and command. Following this logic, doctoral training affords men opportunities to find a sense of accomplishment and achievement through other means (e.g., collaboration with faculty, peers or other professionals on research projects, networking with peers within the larger professional community).

GRC and the advisory working alliance. It was further hypothesized that specific patterns of gender role conflict, namely Restrictive Emotionality, and Success, Power, Competition would predict advisory working alliance among this sample of doctoral students. This hypothesis was rejected as no relationships were found. It was initially speculated that restrictions around emotional expressiveness and an excessive focus on power and control would try the development of a positive working alliance with one's advisor. As the behavioral consequences of gender role conflict have been shown to involve interpersonal contexts (see O'Neil, 2008 for a complete review), an interpretation of this insignificant finding is warranted.

One interpretation for the lack of association rests on the lack of uniformity of the advisory relationship in doctoral training. As discussed earlier, the advisory relationship 
was the chosen for this study as it is arguably the most prevalent and inclusive studentfaculty relationships within the training environment (Schlosser \& Gelso, 2001, 2005). Participants in this study were simply asked to complete the advisory measure referring to 'the faculty member who has the greatest responsibility in helping guide you through your graduate program.'

Perhaps it is precisely the breadth of advisory roles, duties and relationships within and between doctoral programs that contributed to the lack of measured influence in which gender role conflicts were experienced for these men. To exemplify, an advisor who plays a more limited and circumscribed role (e.g., infrequent contact to plan advisee course-load) in training may not develop a relationship within which gender role conflicts might develop. Therefore, although this study did make some exploratory analyses into differences (e.g., gender of advisor, sexual orientation of advisee) within these students' advisory relationships, there likely remained too many factors unaccounted for. These variables may have confounded or spoiled any potential associations between these male traimees experience of gender role conflict and the faculty member whom they identified as their advisor. Perhaps the continued examination and/or control of additional factors within the advisory relationship, (e.g., length of advisory relationship, nature of advisory relationship) may still be needed to effectively narrow the operational definition of 'advisor' and consequently help to elucidate any associations between the advisory working alliance and patterns of gender role conflict.

GRC and multicultural awareness. No specific hypothesis was offered regarding how patterns of gender role conflict might predict or associate with scores on multicultural awareness among this sample of doctoral students. Nonetheless, results 
show that trainees' level of multicultural awareness was associated with levels of gender role conflict. In particular, lower reported restrictive affectionate behavior between men and success, power, competition were influential in predicting higher degrees of multicultural awareness among these male trainees (see Table 6). This finding is consistent with a related line of research linking patterns of gender role conflict with biased and stereotyped attitudes towards marginalized groups (See O’Neil, 2008 for a complete review). In fact, results from 2004 study by Robinson and Schwartz implicate these very two patterns of gender role conflict (i.e., RABBM \& SPC), to negative attitudes towards African Americans among White males.

However, for these male trainees, greater restrictions based on masculine roles (i.e., attitudes around success, difficulties in affective expression with other men) are connected to lower multicultural awareness competency, and vice versa. The definition of multicultural awareness used in this research involved attentiveness to biases, values and assumptions related to others and oneself as cultural beings (Sue, et al., 1992).

First, I will speculate on the association between success, power, competition and multicultural awareness competency. In doctoral training, in particular, growth in the area of multicultural awareness is often encouraged by both classroom discussion of cultural topics (e.g., societal power and privilege) as well as personal and clinical experiences with culturally diverse others. For male trainees, becoming aware of the existence of such cultural phenomena as power and privilege may be challenging to incorporate into one's worldview - as such awareness highlights the cost of their masculinity vis-à-vis marginalized others. Hence, I assume that for men in this sample who overvalue the importance of power and control in relation to success, it is conceivable that a developed 
Table 6

Summary of Multiple Linear Regression Analysis of GRCS Variables Predicting MAKKS-Awareness

GRC Variables $\quad \underline{\text { FTest }}$ Beta Weight

Correlations

FTest

Beta Weight

\begin{tabular}{|c|c|c|c|c|c|c|c|c|}
\hline & $R$ & $R^{2}$ & $F$ & $p$ & $\beta$ & $p$ & Zero-order & Partial \\
\hline GRC Model & .21 & .05 & 3.52 & .008 & & & & \\
\hline $\begin{array}{l}\text { SPC } \\
\text { RE } \\
\text { RABBM } \\
\text { CBWFR } \\
\end{array}$ & & & & & $\begin{array}{r}-.19 \\
.13 \\
-.15 \\
.06 \\
\end{array}$ & $\begin{array}{l}.003 \\
.08 \\
.04 \\
.35 \\
\end{array}$ & $\begin{array}{l}-.17 * * * \\
-.08 \\
-.10 * \\
-.03 \\
\end{array}$ & $\begin{array}{l}-.17 * * \\
-.10 \\
-.12 * \\
-.05\end{array}$ \\
\hline
\end{tabular}

Note. GRCS = Gender Role Conflict Scale; SPC = Success, Power, Competition subscale; RE = Restrictive Emotionalit

subscale; RABBM = Restrictive Affectionate Behavior Between Men subscale; CBWFR = Conflicts Between Work and

Family Relations subscale. MAKKS = Multicultural Awareness, Knowledge, and Skills Survey- Counselor Edition- Revised,

Awareness subscale $* p<.05 ; * * p<.01 ; * * * p<.001$. 
awareness of societal power and privilege might be unwelcome; as it could threaten the stance of power and control that their masculinity is rooted in. Conversely, this finding also makes the case for an opposite interpretation - male trainees less bound by an attitude of success through power and competition, might be more open to new cultural ideas, such as the notion of societal stratification according to power and privilege.

Next, I speculate on the negative association between restrictive affectionate behavior between men and multicultural awareness competency. As mentioned above, it is my belief that multicultural development in doctoral training stems, in part, from personal and clinical exposure to diverse others. Becoming aware of the cultural experiences of diverse others though direct contact implies and openness to connect emotionally and a flexibility to step outside the behavioral conventions of one's culture of origin (e.g., men can kiss each other on the cheek in greeting each other). Therefore, for male trainees whose affective behaviors towards other men are restricted (e.g., expressing feelings verbally and physically), by their masculine role conflict, a barrier exists which might stymie the procurement of novel encounters with diverse others - and subsequent growth in multicultural awareness.

Exploration of within-group differences. As insufficient scholarly interest has been given to this group of men, this research aimed to be especially attentive to differences within the sample. I sought to better understand how, if at all, individual factors differentiated these men according to their gender role conflict and advisory experiences. An exploration into how (a) race, (b) sexual orientation, (c) degree sought, and (d) program specialty differentiated these men according to patterns of gender role conflict, revealed only one significant difference. Specifically, that men who identified as 
gay or bisexual reported less restrictive affectionate behavior between men. This

difference is consistent with past research, which has found that gay men produce lower scores on this pattern of gender role conflict (See O'Neil, 2008 for a complete review). It can also be more intuitively assumed that men, who do not identify as having a heterosexual orientation, at least as compared to their heterosexual counterparts, are less likely to have conflicts around being emotionally and physically intimate with other men - which are often rooted in homophobia.

However, the absence of other significant differences on patterns of conflict within this sample of trainees suggests that men experience unremarkably similar forms and degrees of conflict regardless of their race, or the type of doctoral psychology program (i.e., Psy.D., Ph.D., Clinical, Counseling). With regards to race, existing literature has not yet demonstrated a clear picture of how racial factors, and other aspects of men's diversity, influence gender role conflicts. Rather, what we do know is that GRC is a relevant construct for men across diverse groups and that the construct "was moderated or mediated by racial, ethnic, and acculturation factors (O'Neil, 2008, p. 380)." Thus, within this sample, no discrete differences were noted as to how, if at all, race relates to the gendered experience of male trainees. With regards to type of doctoral program, it was speculated that some patterns of conflict might be exposed due to the differences between training models and specialties (e.g., degree of focus on research versus clinical practice). Yet, despite their distinctions, this result suggests that, as it applies to gender role conflict of male trainees, the similarities across doctoral training programs outweigh any programmatic difference. 
Next, an exploration was made into how (a) participant sexual orientation, (b) gender of advisor, and (c) perceived sexual orientation of advisor differentiated these men according to components of their advisory working alliance. This analysis also revealed only one significant difference, namely that male trainees who identified as heterosexual had greater scores on the Rapport and Identification-Individuation aspects of advisory working alliance. This difference suggests that men who identify as heterosexual are attributing more positive characteristics to their advisory relationship than men of other sexual orientations - particularly around relational aspects and feelings of identification with their advisor.

This finding might be explained by the privilege attached to a heterosexual identity. That is, heterosexual trainees might be more likely to perceive positive relational characteristics (e.g., feeling respected, encouraged, and comfortable) because they hold yet another privileged status (i.e., heterosexual male) and will therefore not likely have to address or negotiate certain difficulties with their advisor along lines of sexual orientation (e.g., to disclose or not). While having a marginalized identity does not necessarily equate to more interpersonal challenges, the presence of such an identity vis-à-vis developing intimate relationships requires attention and energy (e.g., safety assessment around decision to come out or not). If potential issues around sexual identity are present, and not addressed within the advisory relationship, it is unlikely that the development of rapport can proceed. Thus, for heterosexual students who do not need to be as cognizant of this dimension of their identity, there may be fewer obstacles for emotional bonding with their advisor. This may, in turn, translate into more perceived similarities between student and advisor and ultimately a desire to be like him or her. Through this logic, 
sexual identity might be a potential barrier for gay and bisexual trainees in developing the aspects of the advisory relationship that hinge more on relational concerns. What we still do not know is how differences and similarities in sexual orientation affect perceptions of the advisory working alliance within individual dyads (e.g., heterosexual advisor and gay advisee, gay advisee and gay advisor). This line of research is critical so as to move away from conjecture regarding the privileges of a trainee's heterosexual identity within the advisory relationship. Having offered interpretations on the major findings, limitations of this research follow.

\section{Limitations of Current Study}

It is imperative to note several methodological limitations of this study. Perhaps the most significant of these limitations stem from the use of online survey research. The goal of this approach was to access my target population (i.e., male doctoral students currently enrolled in an APA accredited counseling or clinical graduate programs in psychology) and, through unbiased sampling procedures, generate a high response rate. Ideally, this methodology yields a representative sample - with data that are generalizable to the larger theoretical population (in this case, men). In the case of this study, the response rate was less valuable, as my sampling procedures left the number of male trainees who actually received the call for participation is largely unknown.

There are many factors that contribute this uncertainty. First, the exact number of male trainees in this target population was unknown at the time of data collection. It was known how many doctoral programs existed within which these men trained. Thus, program training directors were solicited to forward the call for participation to all men in their program who met criteria. Next, the majority of training directors (70\%) provided 
no confirmation that the call had or had not been forwarded. Finally, the electronic nature of the sampling procedure created possibilities for further error and uncertainty. For example, it is possible that certain training directors did not receive the solicitation email (e.g., incorrect email address, did not see/read email). Many of these possibilities are also true for any eligible male trainees forwarded the call. Hence, as a result of uncertainty regarding how many male trainees received the call for participation, external validity was instead estimated by comparing this sample against APA demographic breakdowns.

After obtaining recent demographic data from APA, it was determined that 5,430 men are currently enrolled in 289 APA-accredited Clinical and Counseling doctoral training programs in the U.S. Therefore, this sample accounts for roughly $18 \%$ of the population. Of this percentage, there were small but significant disparities noted across racial breakdowns. Specifically, this sample is slightly under-representative of Latino, Black, Asian and Native American men and slightly over-representative of White and Bi or Multi-Racial men. Unfortunately, APA data were not available regarding other salient dimensions of identity, such as age or sexual orientation. Therefore, it can not be known how this sample matches the greater population of male trainees along these lines. Taken together, the generalizability of results should be determined commensurate to the degree to which this sample of men characterizes its larger counterpart. In terms of racial proportions, small but significant discrepancies were found to exist. Despite these data not being available for the larger population, it should be remembered that other significant personal differences likely exist (e.g., age) which might also limit representativeness of this sample and the generalizability of results. 
Another limitation involves the fact that that male trainees self-selected to participate in the study, rather than being randomly assigned. Therefore, biases may exist to further weaken representativeness. For example, it is possible that those men in this population who elected not to participate, did so due to an unwillingness to disclose sensitive aspects of one's masculinity. It could be hypothesized that such hesitancy to disclose may be related to higher levels of gender role conflict. Similarly, the overall time commitment and thoughtfulness required to complete certain measures (e.g., multicultural awareness, advisory working alliance) may have deterred those trainees for whom such time was not as expendable (e.g., certain years in doctoral training, those with higher conflict between work and family demands).

In addition, the use of self-report measures likely limited the validity and reliability of the data obtained due to their inherent susceptibility for common method variance. For example, despite the anonymity of this research, it is possible that selfcensoring and/or social desirability played a role in how male trainees responded to certain measures or items. Such potential sources of error and bias are notable in this population due to greater societal restrictions around personal disclosure in general, and more specifically, disclosure of personal difficulties. In addition to social desirability, other ubiquitous measurement artifacts that may have biased results which include the effects of scale length and ambiguous wording.

A limitation of this research, neither rooted in sampling methodology nor form of data collection, involves the creation of a normative male sample against which these trainee's GRCS scores can be compared. In creating this normative sample of men, average GRCS scores from 24 past studies were combined. These specific studies were 
selected so as to approximate this sample of male trainees with regard to the inclusion of certain demographic factors - particularly age and race. However, as available GRCS data are substantial, I also sought to create the largest possible comparison sample so as to increase generalizability. Despite the aim, several limitations of this approach must be considered which have impacted on representativeness and generalizability.

First, between-group comparisons from past studies (e.g., average GRCS scores of Asian and White men) were not run to determine any significant difference. Rather, scores were combined and averaged into the comparison sample. Although, past findings have not definitively established any direct between-group differences on the GRCS with regards to race/ethnicity, they have demonstrated that some differences exist according to age and sexual orientation (see O'Neil, 2008 for a complete review). Furthermore, no between-group differences were found between racial groups in trainee sample. Thus, I aimed to be inclusive of relevant groups in order to best approximate a normative and representative sample for male trainees. The decisions made in creating said normative sample were limited to the aforementioned extant findings and available data so as to preserve the scope and focus of the study. It would have been beneficial, instead, to have considered weighting mean GRC scores depending upon the number of studies and size of samples that were used to create aggregate scores.

Additionally, although I utilized GRCS averages from studies with diverse racial groups - the proportions of these groups to the trainee sample was not statistically exact. For example, the number of GRC studies (and respective sample sizes) of Latino men was disproportionate to those of White men (see Table 1). Hence, if it is empirically determined that Latino men differ significantly from other races on the GRCS, their 
aggregate GRCS scores may be under-representative of those of Latino men in general.

Coupled with the aforementioned limitation that Latino men in this trainee sample (4.3\%) are not equal to the proportion found in the national population of male trainees (9\%) and certainly under-representative of the proportion of Latino men in the U.S. population, comparing the GRCS scores of men of this ethnic group (and other under-represented races in this sample) could have produced misleading results. As stated above, in the aim of creating a representative normative sample, the bind was using the available GRCS data to approximate relevant demography between groups while not sacrificing sample size. It may interest future researchers to statistically tailor a normative male sample to the U.S. population so as to increase the generalizabilty of comparison groups.

A potential limitation was the exclusion of RABBM when hypothesizing patterns of GRC which might predict psychological distress within this sample. Although findings regarding the impact of RABBM on psychological distress (e.g., psychological wellbeing depression) are not as consistent as with other patterns of GRC (e.g., RE), enough evidence exists (see O'Neil, 2008, for a complete review) to have warranted its inclusion in this hypothesis. The failure to implicate RABBM with expressed psychological distress, then, may have been related more to this researcher's own assumptions and stereotypes of male doctoral students - specifically, that when juxtaposed to the other consequences of GRC which male trainees might experience, the degree to which they limit affection with other men would be relatively less impactful.

A final limitation to highlight was the omission of demographic data related to relationship status (e.g., being in a committed relationship, married, children). In hindsight, having collected this information from participants could have provided a 
richer interpretation to the finding that men in this sample are experience high levels of conflict between their professional and personal lives.

\section{Implications for Education and Training}

Several findings of this study, namely the prevalence of psychological distress and conflict between professional and personal spheres among male trainees, lay even greater emphasis on the training and educational needs highlighted by Wester and Vogel (2002) and earlier referenced. Given that men in this sample were found to be both a unique group (regarding certain expressions of male socialization) as well as a group under duress, a greater need exists for training programs to be informed and sensitive to the gendered needs of male students. Any response to these needs must be predicated upon greater support and affirmation for these students unique place within the current demography of psychology training programs.

In terms of education and pedagogy, those directly involved in shaping training program should provide "faculty, staff, and students with current theory and research on men's issues" (Wester and Vogel, 2002, p. 374). At the faculty level, it is recommended that professors "make an effort to include a masculine perspective in their work, value the positive aspects of masculinity, discourage the negative aspects of masculinity, and assist their students in combating the negative or stereotypical reactions of those around them" (p.374). Although somewhat outside of the academic scope of this study, implications for the clinical training (i.e., supervision) of male therapists were recently put forward by MacKinnon, et al. (2011). These scholars suggest that feminist-informed theories of clinical supervision be incorporated with male supervisees. Indeed, the broader training needs of male trainee calls for greater gender competencies across 
academic and clinical realms. Thus, utilizing feminist frameworks to help inform the development of masculine-inclusive psychological education and training would be beneficial. In addition, the suggestion made by these authors, that "male supervisees can act as consultants in training program development" (p. 134) are seconded here. Similarly within academic training, male trainees can begin to effect educational/institutional change by being candid regarding the perceived advantageous and disadvantageous aspects of masculinity as it intersects with the study and practice of psychology. As with other groups who have held or hold a numerical minority within the field (e.g., women, sexual minorities, People of Color) the impetus is here on those interested in the experience of men to bring increased awareness to scholarship and training. Until a greater scholarly base develops, a good start would be with those closest to the lived experience of male trainees.

Regarding educational gatekeeping and competencies in student training, findings suggest that male trainees may be experiencing difficulties and/or symptomotology as related to some combination of personal and professional demands. Thus, both men in doctoral programs and those charged with their training are encouraged to engage in open dialogues around experienced and/or observed difficulties across academic and clinical training domains. With a greater acknowledgment for (and focus on) diminished competency and impairment during training to develop, appropriate interventions and/or accommodations can be implemented in a timely manner.

Anecdotally, it has become more prevalent for men within psychology training programs to create both formal and informal collegial groups. These groups aim to provide opportunities for comradery, support, as well as professional and personal 
development. The formation of such social groups at the programmatic and regional level is encouraged so that men slated to be the future of the field can find kinship among others who share similar issues related to the intersections of personal and professional identity. At the national level, men training to be psychologists are encouraged to become involved in divisions of APA which maintain a commitment to furthering scholarly attention to issues of gender within the larger field (i.e., 51 - Society for the Psychological Study of Men and Masculinity; 35 - Society for the Psychology of Women).

\section{Suggestions for Future Research}

As the study of masculinity among graduate psychology students is in its infancy, many directions and opportunities for future research exist. This study provided a good first step in describing the gendered experience of male graduate students in psychology. First and foremost, results suggest that men training to be psychologists generally experience less conflict around their gender roles than do other men. This is undoubtedly a positive finding and creates the opportunity for future researchers to consider moving beyond a deficit or pathology-driven conceptualization of masculinity within this population. Specifically, using a measure to assess the complexity of masculine norms, such as the Conformity to Masculine Norms Inventory (Mahalik, Locke, et al., 2003) may prove especially valuable as it assesses "both the benefits and costs associated with conformity as well as nonconformity to masculine gender role norms" (Mahalik, Locke, et al., p.4). The need to continue describing the masculinities to which male trainees adhere and do not adhere is invaluable to not only their self-understanding as budding clinicians, but also to those charged with facilitating their professional development. 
While many results of this study (e.g., generally low levels of GRC, nonassociation between GRC and advisory working alliance) invite future researchers to broaden the theoretical and instrumental scope of how masculinity is examined, it remains concerning that male trainees experience more conflict around their work and family lives than do most men. Therefore, it is recommended that continued empirical attention be paid to this stereotyped pattern of masculinity (i.e., CBWFR) as it suggests potentially harmful consequences for the training and eventual careers of these men and, by extension, the public they serve. It would be helpful to better understand what features of this conflict are most germane to male trainees (e.g., disruption of family relationships, marginalization of leisure activities, health difficulties). Perhaps the prevalence of this form of masculine conflict can begin to explain the declining number of men entering doctoral psychology training. Along these lines, the increased level of CBWFR found among trainees in this sample could suggest that said degree of conflict might abate once a transition is made to the role of psychologist. That is, if increased conflict between work and family is mostly related to the pressures and demands of doctoral training, this result would not be found if practicing male psychologists were similarly studied.

However, if CBWFT remains high among practicing male psychologists, other interpretations might be considered - such as, that men in the field of psychology have different (i.e., higher) standards for themselves regarding balancing professional success with involvement and emotionally availability to important others (e.g., partners, children).

Aside from this specific suggestion, the gendered experience of male psychologists, in general, remains a fertile area for future research within the study of 
men and masculinity. Variables related to generational cohort, occupational type, degree of involvement in professional groups, length of practice etc., would be beneficial to examine as they relate to personal and professional variables (e.g., career satisfaction, psychological distress).

Related to the declining number of men entering doctoral psychology training, I encourage future scholars to address this trend in the profession. To do this, additional measures may need to be developed to accurately capture the psychological nuances of males entering into, and functioning in, the roles of a psychologist. An important line of study would involve assessing how the activities and status of a psychologist are perceived by lay people in terms of gender orientation. This information may begin to expose gender-related factors salient for men when deciding whether or not to pursue graduate training in the field. This area of vocational research may serve to better explain what factors attract men to and deter men from graduate psychology training. With these data, researchers can inquire into whether or not certain factors become more or less salient as training progresses.

It is also encouraged that multiple masculine identities be considered in future scholarship. In the study, and with specific regard to GRC, differences between men according to race and sexual orientation were largely unremarkable. Yet, when exploring the advisory working alliance, the sexual orientation of the advisee was found to be significant. Thus, a continued inquiry into how sexual orientation impacts the advisory relationship for male trainees is warranted - with more explicit attention to controlling for the identities of advisor and advisee. Although we now have a better understanding of how certain secondary identities differentiate men with regard to GRC and the advisory 
working alliance, future researchers should be mindful to control for these factors so as to better elucidate their relative importance vis-à-vis other aspects of graduate training. Along these lines, the inclusion of other, often excluded dimensions of personal identity (e.g., age, religion) demand equal scholarly attention within this population.

As stated above, the gendered experience of men in psychology graduate programs is not well understood by empirical research. Given this fact, perhaps a qualitative methodology might be a more helpful way of inquiring into how these men perceive the interaction between their training and masculinities. In this way, studies might be less restricted by instrumentation, potentially more descriptive, and thus, might yield a fuller experiential picture of these men. A qualitative approach may be especially useful in continued examination of masculinity within the advisory relationship. A useful next step would be to use this approach to investigate advisors' and advisees' perceptions of, and experiences with, masculinity as it manifests within the advisory relationship. Future inquiry could also examine masculinity within advisory dyads to expand previous dyadic work (Schlosser \& Kahn, 2007). In sum, with qualitative data in tow, researchers could better translate specific lines of questioning into quantitative methodology and/or instrument development. 
References 
American Psychological Association (2010). APA Commission on Accreditation and APA Office of Program Consultation and Accreditation, Research Committee 2010 Annual Report Online. Retrieved from http://www.apa.org/ed/accreditation/about/ research/index.aspx

American Psychological Association (2009a). 2007 Doctorate employment survey. Data compiled by The Center for Workforce Studies. Retrieved from http://www.apa.org/workforce/publications/07-doc-empl/index.aspx

American Psychological Association (2009b). 2009 Graduate study in psychology: Faculty and student data. Data compiled by The Center for Workforce Studies. Retrieved from http://www.apa.org/workforce/publications/09-gradstudy/index.aspx

American Psychological Association (2008). Debt, salary and career data in psychology: What you need to know. Presented at the 116th Annual Convention of the American Psychological Association, Boston. Data compiled by The Center for Workforce Studies. Retrieved from http://www.apa.org/workforce/presentations/2008-convention.aspx

American Psychological Association. (2003). Guidelines on multicultural education, training, research, practice, and organizational change for psychologists. American Psychologist, 58, 377-402.

Ancis, J. R., \& Szymanski, D. (2001). Awareness of White privilege among White counseling trainees. The Counseling Psychologist, 29, 548-569. 
Blazina, C., \& Watkins, C. E. (2000). Separation/individuation, parental attachment, and male gender conflict: Attitudes toward the feminine and the fragile masculine self. Psychology of Men and Masculinity, 1, 126-132.

Bowen, K. (1983). Protestants in a Catholic state: Ireland's privileged minority. Montreal, CA: McGill-Queen's University Press.

Constantine, M. G. (2002). Predictors of satisfaction with counseling: Racial and ethnic minority clients' attitudes toward counseling and their ratings of their counselors' general and multicultural counseling competence. Journal of Counseling Psychology, 49, 255-263.

D’Andrea, M., Daniels, J., \& Heck, R. (1991). Evaluating the impact of multicultural counseling training. Journal of Counseling \& Development, 70, 143-150.

Dodson, T., \& Borders, D. (2006). Men in traditional and nontraditional careers: Gender role attitudes, gender role conflict, and job satisfaction. Career Development Quarterly, 54, 283-296.

Doherty, W. J. (1991). Beyond reactivity and the deficit model of manhood: A commentary on articles by Napier, Pittman and Gottman. Journal of Marital and Family Therapy, 17, 29-32.

Englar-Carlson, M., \& Vandiver, B. (2002, August). Comparing the dimensionality of the GRCS, MGRS, and SRES. In J. M. O’Neil \& G. E. Good (Chairs), Gender role conflict research: Empirical Studies and 20 year summary. Symposium conducted at the annual meeting of the American Psychological Association, Chicago, IL. 
Enns, C. (2000). Gender issues in counseling. In S. Brown \& R. Lent (Eds.), Handbook of counseling psychology (3rd ed., pp. 601-638). New York, NY: John Wiley.

Evans, J. (1997). Men in nursing: Issues of gender segregation and hidden advantage. Journal of Advanced Nursing, 26, 226-231.

Faul, F., Erdfelder, E., Lang, A. G., \& Buchner, A. (2007). G*Power 3: A flexible statistical power analysis program for the social, behavioral, and biomedical sciences. Behavior Research Methods, 39, 175-191.

Fitzgerald, L. F., \& Osipow, S. H. (1986). An occupational analysis of counseling psychology: How special is the specialty? American Psychologist, 41, 535-544.

Forrest, L., Elman, N. S., Gizara, S., \& Vacha-Haase, T. (1999). Trainee impairment: A review of identification, remediation, dismissal, and legal issues. The Counseling Psychologist, 27, 627-686.

Fuertes, J. N., \& Brobst, K. (2002). Clients' ratings of counselor multicultural competency. Cultural Diversity and Ethnic Diversity Psychology, 8, 214-233.

Gelso, C., \& Fretz. B. (2001). Counseling psychology ( $2^{\text {nd }}$ ed). Fort Worth, TX: Harcourt College Publishers.

Good, G. E., Robertson, J. M., O’Neil, J. M., Fitzgerald, L. F., Stevens, M., DeBord, K,... Braverman, D.G. (1995). Male gender role conflict: Psychometric issues and relations to psychological distress. Journal of Counseling Psychology, 42, 3-10.

Good, G. E., \& Sherrod, N. B. (2001). Men's problems and effective treatment. In G. R. Brooks \& G. E. Good (Eds.), The new handbook of psychotherapy and counseling with men (pp. 22-40). San Francisco, CA: Jossey-Bass. 
Gottfredson, L. S. (1981). Circumscription and compromise: A developmental theory of occupational aspirations. Journal of Counseling Psychology, 28, 545-579.

Gottfredson, L. S. (1997). Assessing gender-based circumscription of occupational aspirations. Journal of Career Assessment, 5(4), 419-441.

Hart, B. (2009, August). The Future of the Psychology Workforce-Statistics and Trends. Presented at the 117th Annual Convention of the American Psychological Association, Toronto, CA. Retrieved from http://www.apa.org/workforce/ presentations/2009-convention.aspx

Hayes, M. M. (1985). Counselor sex-role values and effects on attitudes toward, and treatment of non-traditional male clients. Diss. Ohio State University, 1985. Dissertation Abstracts International, 45, 3072.

Hays, D. G. (2008). Assessing multicultural competence in counselor trainees: A review of instrumentation and future directions. . Journal of Counseling \& Development, $86,95-101$.

Hays, D. G., Dean, J. K., \& Chang, C. Y. (2007). Addressing privilege and oppression in counselor training and practice: A qualitative analysis. Journal of Counseling \& Development, 85, 317-324.

Helms, J. (1984). Toward a theoretical explanation of the effects of race on counseling: A black and white model. The Counseling Psychologist, 12, 153-165.

Helms, J. E., \& Cook, D. A. (1999). Using race and culture in counseling and psychotherapy: Theory and process. Boston, MA: Allyn \& Bacon. 
Johnson, W. B., \& Campbell, C. D. (2002). Character and fitness requirements for professional psychologists: Are there any? Professional Psychology: Research and Practice, 33, 46-53.

Johnson, W. B., \& Huwe, J. M. (2002). Toward a typology of mentorship dysfunction in graduate school. Psychotherapy: Theory/Research/Practice/Teaching, 39, 44-55.

Jome, L. M., \& Tokar, D. M. (1997). Dimensions of masculinity and major choice traditionality. Journal of Vocational Behavior, 52, 120-134.

Kaslow, N. J. (2004). Competencies in professional psychology. American Psychologist, 59, 774-781.

Kim, B. S. K., Cartwright, B. Y., Asay, P. A., \& D’Andrea, M. J. (2003). A revision of the Multicultural Awareness, Knowledge, and Skills Survey-Counselor Edition. Measurement and Evaluation in Counseling and Development, 36, 161-180.

Kiselica, M. S. (2001). A male-friendly therapeutic process with school-age boys. In G. R. Brooks \& G. E. Good (Eds.), The new handbook of psychotherapy and counseling with men (Vol. 1, pp. 43-58). San Francisco, CA: Jossey-Bass.

Kiselica, M. S., Englar-Carlson, M., Horne, A. M., \& Fisher, M. (2008). A positive psychology perspective on helping boys. In M. S. Kiselica, M. Englar-Carlson, \& A. M. Horne (Eds.), Counseling troubled boys: A guidebook for practitioners (pp. 31 -48). New York, NY: Routledge.

Knox, S., Schlosser, L. Z., Pruitt, N. T. \& Hill, C. E. (2006). A qualitative examination of graduate advising relationships: The advisor perspective. The Counseling Psychologist, 34, 489-518. 
Lambert, M. J., Burlingame, G. M., Umphress, V., Hansen, N .B., Vermeersch, D. A., Clouse, G. C.,... Yanchar, S. C. (1996). The reliability and validity of the Outcome Questionnaire. Clinical Psychology and Psychotherapy, 3, 249-258.

Lambert, M. J., Morton, J. J., Hatfield, D., Harmon, C., Hamilton, S., Reid, R. C.,... Burlingame, G. M. (2004). Administration and Scoring Manual for the Outcome Questionnaire-45. Orem, UT: American Professional Credentialing Services.

Liu, W. M. (2005). The study of men and masculinity as an important multicultural competency consideration. Journal of Clinical Psychology, 61, 685-697.

Liu, W. M., \& Pope-Davis, D. B. (2003). Moving from diversity to multiculturalism: Exploring power and its implications for multicultural competence. In D.B. PopeDavis, H.L.K. Coleman, W.M. Liu, \& R.L. Toporek (Eds.), Handbook of multicultural competencies in counseling and psychology (pp. 90-102). Thousand Oaks, CA: Sage.

Liu, W. M, Sheu, H., \& Williams, K. (2004). Multicultural competency in research: Examining the relationships among multicultural competencies, research training and self efficacy, and the multicultural environment. Cultural Diversity and Ethnic Minority Psychology, 10, $324-339$.

MacKinnon, C.J., Bhatia, M., Sunderani, S., Affleck, W., \& Smith, N.G. (2011). Opening the dialogue: Implications of feminist supervision theory with male supervisees. Professional Psychology: Research and Practice, 42, 130-136.

Mahalik, J. R., Good, G. E., \& Englar-Carlson, M. (2003). Masculinity scripts, presenting concerns, and help seeking: Implications for practice and training. Professional Psychology: Research and Practice, 34, 123-131. 
Mahalik, J. R., Locke, B. D., Ludlow, L. H., Diemer, M. A., Scott, R. P., Gottfried, M., \& Freitas, G. (2003). Development of the Conformity to Masculine Norms Inventory. Psychology of Men and Masculinity, 4, 3-25.

Mintz, L., \& O’Neil, J. M. (1990). Sex, gender role, and the process of psychotherapy: Theory and research. Journal of Counseling and Development, 68, 381-387.

Moradi, B., Tokar, D. M., Schaub, M., Jome, L. M., \& Serna, G. S. (2000). Revisiting the structural validity of the gender role conflict scale. Psychology of Men and Masculinity, 1, 62-69.

Mueller, R., Lambert, M. J., \& Burlingame, G. (1998). The Outcome Questionnaire: A confirmatory factor analysis. Journal of Personality Assessment, 70, 248-262.

Munley, P. H., Pate, W. E., \& Duncan, L. E. (2008). Demographic, educational, employment, and professional characteristics of counseling psychologists. The Counseling Psychologist, 36, 250-280.

O’Neil, J. M. (n.d). The Gender Role Conflict Research Program. Retrieved from http://jimoneil.uconn.edu/GenderHome.html

O’Neil, J. M. (1981a). Male sex-role conflict, sexism, and masculinity: Implications for men, women, and the counseling psychologist. The Counseling Psychologist, 9, 61-80.

O'Neil, J. M. (1981b). Patterns of gender role conflict and strain: Sexism and fear of femininity in men's lives. Personnel and Guidance Journal, 60, 203-210.

O’Neil, J. M. (1982). Gender role conflict and strain in men's lives: Implications for 
psychiatrists, psychologists, and other human service providers. In K. Solomon \& N. B. Levy (Eds.), Men in transition: Changing male roles, theory, and therapy (pp. 5-44). New York, NY: Plenum.

O'Neil, J. M. (1990). Assessing men's gender role conflict. In D. Moore \& F. Leafgren (Eds.), Men in conflict: Problem solving strategies and interventions (pp. 23-38). Alexandria, VA: American Association for Counseling and Development.

O’Neil, J. M. (2008). Summarizing 25 years of research on men's gender role conflict using the gender role conflict scale: New research paradigms and clinical implications. The Counseling Psychologist, 36, 358-445.

O’Neil, J. M., \& Egan, J. (1992a). Men's and women's gender role journeys: Metaphor for healing, transition, and transformation. In B. Wainrib (Ed.), Gender issues across the life cycle (pp. 107-123). New York, NY: Springer.

O’Neil, J. M., \& Egan, J. (1992b). Men's gender role transitions over the life span: Transformations and fears of femininity. Journal of Mental Health Counseling, $14,305-324$.

O’Neil, J. M., \& Fishman, D. (1992). Adult men's career transitions and gender role themes. In H. D. Lee \& Z. B. Leibowitz (Eds.), Adult career development: Concepts, issues, and practices (2nd ed., pp. 132-162). Alexandria, VA: ACA Press.

O'Neil, J. M., Good, G. E., \& Holmes, S. (1995). Fifteen years of theory and research on men's gender role conflict: New paradigms for empirical research. In R. Levant \& W.Pollack (Eds.), The new psychology of men (pp. 164-206). New York, NY: Basic Books. 
O’Neil, J. M., Helms, B. J., Gable, R. K., David, L., \& Wrightsman, L. S. (1986). Gender Role Conflict Scale: College men's fear of femininity. Sex Roles, 14, 335-350.

Pedersen, P. B. (1991). Multiculturalism as a generic approach to counseling. Journal of Counseling and Development, 70, 6-12.

Peterson, D. R. (1976). Need for the doctor of psychology degree in professional psychology. American Psychologist, 31, 792-798.

Pion, G. M., Mednick, M. T., Astin, H. S., Iijima Hall, C. C., Kentel, M. B, Keita,... Kelleher, J. C. (1996). The shifting gender composition of psychology: Trends and implications for the discipline. The American Psychologist, 51, 509-528.

Pleck, J. (1981). The myth of masculinity. Cambridge, MA: MIT Press.

Pleck, J. H. (1995). The gender role strain paradigm: An update. In R. F. Levant \&W. S. Pollack (Eds.), A new psychology of men (pp. 11-32). New York, NY: Basic Books.

Ponterotto, J. G., Gretchen, D., Utsey, S. O., Rieger, B., \& Austin, R. (2002). A revision of the Multicultural Counseling Awareness Scale. Journal of Multicultural Counseling and Development, 30, 153-180.

Pope-Davis, D. B., Coleman, H. L. K., Liu, W. M., \& Toporek, R. (Eds.). (2003). The handbook of multicultural competencies in counseling and psychology. Thousand Oaks, CA: Sage.

Rice, K. G., Choi, C., Zhang, Y., Villegas, J., Ye, H. J., Anderson, D.,... Bigler, M. (2009). International student perspectives on graduate advising relationships. Journal of Counseling Psychology, 56, 376-391.

Robinson, D. T., \& Schwartz, J. P. (2004). Relationship between gender role conflict and 
Attitudes toward women and African Americans. Psychology of Men and Masculinity, 5, 65-71.

Rochlen, A. B. (2005). Men in (and out) of therapy: Central concepts, emerging directions, and remaining challenges. Journal of Clinical Psychology, 61, 627631.

Rochlen, A. B., Blazina, C., \& Raghunathan, R. (2002). Gender role conflict, attitudes toward career counseling, career decision making, and perceptions of career advertising brochures. Psychology of Men and Masculinity, 3, 127-137.

Rochlen, A. B., \& O'Brien, K. M. (2002). The relation of male gender role conflict and attitudes toward career counseling to interest in and preference for career counseling styles. Psychology of Men and Masculinity, 3, 9-21.

Rogers, M. R., Hoffman, M. A., \& Wade, J. (1998). Notable multicultural training in APA-approved counseling psychology and school psychology programs. Cultural Diversity and Mental Health, 4, 212-226.

Schlosser, L. Z. \& Foley, P. F. (2008). Ethical issues in Multicultural Student-Faculty Mentoring Relationships in Higher Education. Mentoring and Tutoring: Partnership in Learning, 16, 63-75.

Schlosser, L. Z. \& Gelso, C. J. (2001). Measuring the working alliance in advisor-advisee relationships in graduate school. Journal of Counseling Psychology, 48, 157-167.

Schlosser, L. Z. \& Gelso, C. J. (2005). The Advisory Working Alliance Inventory Advisor Version: Scale Development and Validation. Journal of Counseling Psychology, 52, 650-654. 
Schlosser, L. Z. \& Kahn, J. H. (2007). Dyadic perspectives on advisor-advisee relationships in counseling psychology doctoral programs. Journal of Counseling Psychology, 54, 211-217.

Schlosser, L. Z., Knox, S., Moskovitz, A. R., \& Hill, C. E. (2003). A qualitative study of the graduate advising relationship: The Advisee Perspective. Journal of Counseling Psychology, 50, 178-188.

Shakow, D. (1965). Seventeen years later: Clinical psychology in the light of the 1947 Committee on Training in Clinical Psychology report. American Psychologist. 20, 353-362.

Sharpe, M. J., \& Heppner, P. P. (1991). Gender role, gender role conflict, and psychological well-being in men. Journal of Counseling Psychology, 38, 323-330.

Sharpe, M. J., Heppner, P. P., \& Dixon, W. A. (1995). Gender role conflict, instrumentality, expressiveness, and well-being in adult men. Sex Roles, 33, 1-18.

Smiler, A. P. (2004). Thirty years after the discovery of gender: Psychological concept and measures of masculinity. Sex Roles, 50, 15-26.

Sodowsky, G. R., Taffe, R. C., Gutkin, T., \& Wise, S. L. (1994). Development and applications of the Multicultural Counseling Inventory. Journal of Counseling Psychology, 41, 137-148.

Sue, D. W., Arredondo, P., \& McDavis, R. J. (1992). Multicultural counseling competencies and standards: A call to the profession. Journal of Counseling and Development, 20, 644-688.

Sue, D. W., \& Sue, D. (2003). Counseling the culturally diverse: Theory and practice (4th ed.). New York: John Wiley. 
Thompson, E. H., Pleck, J. H., \& Ferrera, D. L. (1992). Men and masculinity: Scales for masculinity ideology and masculinity-related constructs. Sex Roles, 27, 573-607.

Tokar, D. M., \& Jome, L. M. (1998). Masculinity, vocational interests, and career choice traditionality:Evidence for a fully mediated model. Journal of Counseling Psychology, 45, 424-435.

Tori, C. D., \& Ducker, D. G. (2004). Sustaining the commitment to multiculturalism: A longitudinal study in a graduate psychology program. Professional Psychology: Research and Practice, 35, 649-657.

Wester, S. R, Christianson, H. F., Fouad, N. A., \& Santiago-Rivera, A. Z (2008). Information processing as problem solving: A collaborative approach to dealing with Students exhibiting insufficient competence. Training and Education in Professional Psychology, 28, 193-201.

Wester, S. R., \& Vogel, D. L. (2002). Working with masculine mystique: Male gender role conflict, counseling self-efficacy and the training of male psychologists. Professional Psychology: Research and Practice, 33, 370-376.

Wester, S. R., Vogel, D. L., \& Archer, J. (2004). Male restricted emotionality and counseling supervision. Journal of Counseling and Development, 82, 91-98.

Wester, S. R., Vogel, D. L., Pressly, P. K., \& Heesacker, M. (2002). Sex differences in emotion: A critical review of the literature and implications for counseling psychology. The Counseling Psychologist, 30, 629-651.

Wilkinson, W. W. (2004). Authoritarian hegemony, dimensions of masculinity, and male antigay attitudes. Psychology of Men and Masculinity, 5, 121-131.

Wisch, A., \& Mahalik, J. R. (1999). Male therapists' clinical bias: Influence of client 
gender roles and therapist gender role conflict. Journal of Counseling Psychology, $46,51-60$.

Yamamoto, K. (1963). Counseling psychologists-Who are they? Journal of Counseling Psychology, 10, 211-221.

Zachar, P. \& Leong, F. T. L. (2000). A 10-Year longitudinal study of scientist and practitioner interests in psychology: Assessing the Boulder model. Professional Psychology: Research and Practice, 31, 575-580. 
Appendix A

Demographic Questionnaire 


\section{Please provide some demographic information:}

1. Age:

2. Race:

3. Ethnic/Cultural Background:

4. Sexual Orientation:

5. Primary Religious Orientation, if any:

6. Current Terminal Degree Sought: (check one) Ph.D. Psy.D.

In the specialty area of: (check one)

Counseling Psychology Clinical Psychology

7. In what region of the United States is your doctoral program located?

South (Alabama, Florida, Georgia, Louisiana, Mississippi)

Mid-South (Kentucky, North Carolina, South Carolina, Tennessee, Virginia)

South Central (Arkansas, Kansas, Missouri, Oklahoma, Texas)

Southwest (Arizona, Colorado, Nevada, New Mexico, Utah)

Northwest (Idaho, Montano, Oregon, Washington, Wyoming)

Pacific West (California, Hawaii, Alaska)

Upper Plains (Iowa, Minnesota, Nebraska, North Dakota, South Dakota)

Great Lakes (Michigan, Ohio, Wisconsin, Illinois, Indiana)

Mid Atlantic (Delaware, Maryland, New Jersey, New York, Pennsylvania, West Virginia)

New England (Connecticut, New Hampshire, Maine, Rhode Island, Massachusetts, Vermont)

8. Number of training years completed in your doctoral program:

9. Number of completed courses specifically on multicultural counseling:

10. Sex of your primary advisor* * the advisor most responsible for your progress

11. Sexual Orientation of your primary advisor unknown)

12. Length of current advisory relationship:

13. Number of advisory relationships to date during your doctoral training:

14. Length of longest advisory relationship, if not your most current or only: 
Appendix B

Gender Role Conflict Scale (GRCS) 
Instructions: In the space to the left of each sentence below, write the number that most closely represents the degree that you Agree or Disagree with the statement. There is no right or wrong answer to each statement; your own reaction is what is asked for.

\begin{tabular}{|cccccc|}
\hline 1 & 2 & 3 & 4 & 5 & $\begin{array}{c}6 \\
\text { Strongly } \\
\text { Agree } \\
\text { Disagree }\end{array}$
\end{tabular}

1. Moving up the career ladder is important to me.

2. I I have difficulty telling others I care about them.

3 Verbally expressing my love to another man is difficult for me.

4. I I I feel torn between my hectic work schedule and caring for my health.

5. ___ Making money is part of my idea of being a successful man.

6. ___ Strong emotions are difficult for me to understand.

7. Affection with other men makes me tense.

8. I__ I sometimes define my personal value by my career success.

9. ____ Expressing feelings makes me feel open to attack by other people.

10. Expressing my emotions to other men is risky.

11. ___ My career, job, or school affects the quality of my leisure or family life.

12. I__ I evaluate other people's value by their level of achievement and success.

13. _ Talking about my feelings during sexual relations is difficult for me.

14. ___ I worry about failing and how it affects my doing well as a man.

15. ___ I have difficulty expressing my emotional needs to my partner. 


\begin{tabular}{|cccccc|}
\hline 1 & 2 & 3 & 4 & 5 & 6 \\
$\begin{array}{c}\text { Strongly } \\
\text { Disagree }\end{array}$ & & & & & $\begin{array}{l}\text { Strongly } \\
\text { Agree }\end{array}$ \\
\hline
\end{tabular}

16. ___ Men who touch other men make me uncomfortable.

17. Finding time to relax is difficult for me.

18. ___ Doing well all the time is important to me.

19. I _ I have difficulty expressing my tender feelings.

20. ___ Hugging other men is difficult for me.

21. ___ I often feel that I need to be in charge of those around me.

22. Telling others of my strong feelings is not part of my sexual behavior.

23. Competing with others is the best way to succeed.

24. Winning is a measure of my value and personal worth.

25. I I I often have trouble finding words that describe how I am feeling.

26. I I I am sometimes hesitant to show my affection to men because of how others might perceive me.

27. __ My needs to work or study keep me from my family or leisure more than would like.

28. ___ I strive to be more successful than others.

29. ___ I do not like to show my emotions to other people.

30. Telling my partner my feelings about him/her during sex is difficult for me.

31. ___ My work or school often disrupts other parts of my life (home, family, health leisure. 


\begin{tabular}{|cccccc|}
\hline 1 & 2 & 3 & 4 & 5 & 6 \\
Strongly & & & & & $\begin{array}{l}\text { Strongly } \\
\text { Agree }\end{array}$ \\
Disagree & & & & & \\
\hline
\end{tabular}

32. __ I am often concerned about how others evaluate my performance at work or school.

33. ___ Being very personal with other men makes me feel uncomfortable.

34. Being smarter or physically stronger than other men is important to me.

35. ___ Men who are overly friendly to me make me wonder about their sexual preference (men or women).

36. ___ Overwork and stress caused by a need to achieve on the job or in school, affects/hurts my life.

37. ___ I like to feel superior to other people. 


\section{Appendix C}

Multicultural Awareness, Knowledge, and Skills Survey- Counselor Edition-Revised (MAKSS-CE-R) - Awareness Subscale 
Instructions: In the space to the left of each sentence below, write the number that most closely represents the degree that you Agree or Disagree with the statement. There is no right or wrong answer to each statement; your own reaction is what is asked for.

\begin{tabular}{|cccc|}
\hline 1 & 2 & 3 & 4 \\
Strongly & & & Strongly \\
Disagree & & & Agree \\
\hline
\end{tabular}

1. ___ Promoting a client's sense of psychological independence is usually a safe goal to strive for in most counseling situations.

2. ___ Even in multicultural counseling situations, basic implicit concepts such as "fairness" and "health" are not difficult to understand.

3. How would you react to the following statement? In general, counseling services should be directed towards assisting clients to adjust to stressful environmental situations.

4. W__ While a person's natural support system (i.e., family, friends, etc.) plays an important role during a period of personal crisis, formal counseling services tend to result in more constructive outcomes.

5. The human services professions, especially counseling and clinical psychology, have failed to meet the mental health needs of ethnic minorities.

6. The effectiveness and legitimacy of the counseling profession would be enhanced if counselors consciously supported universal definitions of normality.

7. Racial and ethnic persons are underrepresented in clinical and counseling psychology. 


\begin{tabular}{|cccc|}
\hline 1 & 2 & 3 & 4 \\
$\begin{array}{c}\text { Strongly } \\
\text { Disagree }\end{array}$ & & & Strongly \\
& & & Agree \\
\hline
\end{tabular}

8. In In counseling, clients from different ethnic/cultural backgrounds should be given the same treatment that White mainstream clients receive.

9. ___ The criteria of self-awareness, self-fulfillment, and self-discovery are important measures in most counseling sessions.

10. _ The difficulty with the concept of "integration" is its implicit bias in favor of the dominant culture. 
Appendix D

Advisory Working Alliance Index- Student Version (AWAI-S) 
Instructions: These 30 items pertain to your perceptions about your relationship with your advisor. For the purposes of this study, the term advisor is referring to the faculty member who has the greatest responsibility in helping guide you through your graduate program (e.g. advisor, major professor, committee chair, dissertation chair). Please respond to the items using the following scale:

\begin{tabular}{|ccccc|}
\hline 1 & 2 & 3 & 4 & 5 \\
Strongly & & Neutral & & Strongly \\
Disagree & & & & Agree \\
\hline
\end{tabular}

1. I I get the feeling that my advisor does not like me very much.

2. ___ My advisor introduces me to professional activities (E.g. conferences, submitting articles for journal publication)

3. I I do not want to be like my advisor.

4. My advisor welcomes my input into our discussions.

5. ___ My advisor helps me conduct my work within a plan.

6. I I t tend to see things differently from my advisor.

7. ___ My advisor does not encourage my input into our discussions.

8. My advisor has invited me to be a responsible collaborator in his/her own work.

9. ___ I do not want to feel similar to my advisor in the process of conducting work. 
10. ___ My advisor is not kind when commenting about my work.

11. My advisor helps me establish a timetable for the tasks of my graduate training.

12. ___ My advisor and I have different interests.

13. ___ I do not feel respected by my advisor in our work together.

14. ___ My advisor is available when I need her/him.

15. ___ I feel like my advisor expects too much from me.

16. ___ My advisor offers me encouragement for my accomplishments.

17. ___ Meetings with my advisor are unproductive.

18. I I I do not think that my advisor believes in me.

19. ___ My advisor facilitates my professional development through networking.

20. ___ My advisor takes my ideas seriously.

21. ___ My advisor does not help me stay on track in our meetings.

22. I I I do not think that my advisor has my best interests in mind.

23. ___ I learn from my advisor by watching her/him.

24. ___ I feel uncomfortable working with my advisor.

25. ___ I am an apprentice of my advisor.

26. ___ I am often intellectually "lost" during my meetings with my advisor.

27. I _ I consistently implement suggestions made by my advisor.

28. ___ My advisor strives to make program requirements as rewarding as possible.

29. ___ My advisor does not educate me about the process of graduate school.

30. ___ My advisor helps me recognize areas where I can improve. 
Appendix E

Outcome Questionnaire (OQ-45.2) 
Instructions: Looking back over the last week, including today, help us understand how you have been feeling. Read each item carefully and mark the circle under the category that best describes your current situation. For this questionnaire, work is defined as employment, school, housework, volunteer work, and so forth.

\begin{tabular}{|ccccc|}
\hline 4 & 1 & 2 & 3 & 4 \\
Never & Rarely & Sometimes & Frequently & Almost Always \\
\hline
\end{tabular}

1. I I get along well with others.

2. I I tire quickly.

3 I I feel no interest in things.

4. I I feel stressed at work/school.

5. ____ I blame myself for things.

6. ___ I feel irritated.

7. I I f feel unhappy in my marriage/significant relationship.

8. I I I have thoughts of ending my life.

9. ___ I feel weak.

10. __ I feel fearful.

11.___ After heavy drinking, I need a drink the next morning to get going. (If you do not drink mark "never")

12. ___ I find my work/school satisfying.

13. ___ I am a happy person.

14. I I work/study too much.

15. ___ I feel worthless. 


\begin{tabular}{|ccccc|}
\hline 4 & 1 & 2 & 3 & 4 \\
Never & Rarely & Sometimes & Frequently & Almost Always \\
\hline
\end{tabular}

16. I I I am concerned about family troubles.

17.___ I have an unfulfilling sex life.

18. ___ I feel lonely.

19.___ I have frequent arguments.

20. ___ I feel loved and wanted.

21. I__ I enjoy my spare time.

22. ___ I have difficulty concentrating.

23. ___ I feel hopeless about the future.

24. ___ I like myself.

25. ___ Disturbing thoughts come into my mind that I cannot get rid of.

26. ___ I feel annoyed by people who criticize my drinking (or drug use). (If not applicable mark "never")

27. I have an upset stomach.

28. I I I am not working/studying as well as I used to.

29. ___ My heart pounds too much.

30. I I have trouble getting along with friends and close acquaintances.

31. I I I am satisfied with my life.

32. I I have trouble at work/school because of drinking or drug use. (If not applicable mark “never”)

33. I I f feel that something bad is going to happen. 


\begin{tabular}{|ccccc|}
\hline 4 & 1 & 2 & 3 & 4 \\
Never & Rarely & Sometimes & Frequently & Almost Always \\
\hline
\end{tabular}

34. __ I have sore muscles.

35. __ I feel afraid of open spaces, of driving, or being on busses, subways, and so forth.

36. I I I feel nervous.

37. __ I feel my love relationships are full and complete.

38. ___ I feel that I am not doing well at work/school.

39. I I have too many disagreements at work/school.

40. ___ I feel something is wrong with my mind.

41.___ I have trouble falling asleep or staying asleep.

42. ___ I feel blue.

43. I I am satisfied with my relationships with others.

44. __ I feel angry enough at work/school to do something I might regret.

45. ___ I have headaches. 
Appendix F

INFORMED CONSENT: Male Psychology Doctoral Students 
Dear Student,

I am conducting a study of the gendered experience of male psychology doctoral students in graduate training. Specifically, I am exploring these students' levels of gender role conflict (GRC) and it's relationships with the advisory relationship, multicultural competence and distress. I know your time is valuable, so this study was designed to be brief. Your participation will only require approximately $\mathbf{1 5}$ minutes of your time!

Your participation is completely voluntary and will not suffer any negative consequences if you decide not to participate. Your participation will also be kept completely anonymous. All electronic data from this research will be confidentially stored on the primary investigator's USB key, which will be kept in a locked file cabinet for five years. Only my advisor and I will have access to the data.

If you agree to participate, please complete the brief survey online by following the link below:

\section{XXXXXXXXXXXXXX}

I believe that participating in this research could benefit (a) current male doctoral students, and (b) those involved in graduate psychology training programs by describing men in psychology training and how their masculinity impacts training.

Your completion of the measures will serve as your consent to participate. Of course, you are free to withdraw from the study at any time without penalty. Feel free to contact the principal investigator, Christopher Sbaratta, if you have any questions or concerns about the study.

Sincerely,

Christopher A. Sbaratta, M.A.

Primary Investigator

908-803-3655

Christopher.Sbaratta@shu.edu

csbaratta@gmail.com
Lewis Z. Schlosser, Ph.D., ABPP

Associate Professor and Dissertation Mentor 973-275-2503

Lewis.Schlosser@shu.edu 
Appendix G

Recruitment Letter 
Däll D:

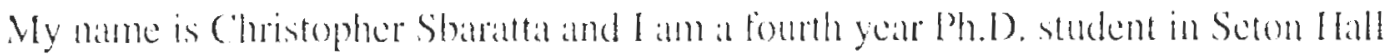
Iniversity's comnseling psychology program. Under the supervision of Lewis $\%$. Schlosicr, Ph.D., ABPP,

I am conducting a study exploring male psychology doctoral students - how gender contlict relates to dimensions of their training. namely advisory working alliance, multicultural awareness and psychological distress.

lam contacting you hoping that you will forward my call for participants (below) to male students in your program and/or other students you know who meet the criteria or may be interested.

If you would like to speak with the principal investigator, Christopher Sbaratta, about this survey or our research, please contact him at Christopher.Sbaratta@shu.edu or (908) 80)33655 .

Thank you in advance for your consideration, time and help

Regards,

Christopher A. Sbaratta, M.A., Principal Investigator Lewis Z. Schlosser, Ph.D., ABPP, Dissertation Mentor Counseling Psychology Ph,D. Program

Seton Hall University

400 South Orange Avenue

South Orange, NJ 07079 


\title{
SEEKING WALE PSYCHOLOGY DOCIORAL STUDENTS
}

\author{
ARE YOU A WAN LEROLLED IN AN APA-AC CREDITED \\ CLINICALOR COUNSLLING DOCTORAL PROGRAW?
}

\section{IIELP US BFGIN TO DFSCRIBE, YOUR EXPERIENCE?}

\section{PARTICIPATE IN A NATIONAL ONLINE SURVEY OF MALE DOCTORAL STUDENTS!}

The survey takes approximately 15 minutes and participation is entirely anonymous.

With the permission of the Seton Hall University Institutional Review Board, I am conducting a study of the gendered experience of male psychology doctoral students in graduate training. Specifically, I am exploring levels of gender role conflict (GRC) and it's relationships with variables related to the psychology training environment.

I know your time is valuable, so this study was designed to be brief. Your participation will only require approximately $\mathbf{1 5}$ minutes of your time!

Follow the link below to access the survey.

Imps:/Ww w surveynonkey.com/s/NCXWNBW

If you would like to speak with the principal investigator, Christopher Sbaratta, about this survey or our research, please contact him at Christopher.Sbaratta@shu.edu or (908) 8033655 .

Thank you for your consideration and time.

Regards,

Christopher A. Sbaratta, M.A., Principal Investigator Lewis Z. Schlosser, Ph.D., ABPP, Dissertation Mentor Counseling Psychology Ph.D. Program

Seton Hall University

4(0) South Orange Averenue 